\title{
Instability Process of Crack Propagation and Tunnel Failure Affected by Cross-Sectional Geometry of an Underground Tunnel
}

\author{
Xianjie Hao $\mathbb{D}^{1},{ }^{1,2,3,4,5}$ Shaohua Wang, ${ }^{5,6}$ Duoxiang Jin ${ }^{D},{ }^{5}$ Bo Ren, ${ }^{5,7,8,9}$ Xiangyang Zhang, \\ Kailong Qiu $\mathbb{D},{ }^{5,6}$ and Yingjie Fan ${ }^{5,10}$ \\ ${ }^{1}$ State Key Laboratory of Coal Resources and Safe Mining, China University of Mining and Technology (Beijing), \\ Beijing 100083, China \\ ${ }^{2}$ State Key Laboratory of Water Resource Protection and Utilization in Coal Mining, Beijing 100083, China \\ ${ }^{3}$ Key Laboratory of Safety and High-efficiency Coal Mining, Ministry of Education, Anhui University of Science and Technology, \\ Huainan 232001, China \\ ${ }^{4}$ Beijing Key Laboratory for Precise Mining of Intergrown Energy and Resources, \\ China University of Mining and Technology (Beijing), Beijing 100083, China \\ ${ }^{5}$ School of Energy and Mining Engineering, China University of Mining and Technology (Beijing), Beijing 100083, China \\ ${ }^{6}$ CAS Key Laboratory of Mechanical Behavior and Design of Materials, University of Science and Technology of China, Hefei, \\ Anhui 230026, China \\ ${ }^{7}$ Coal Mining National Engineering Technology Research Institute, Huainan 232000, China \\ ${ }^{8}$ State Key Laboratory of Deep Coal Mining and Environment Protection, Anhui University of Science and Technology, \\ Huainan 232000, China \\ ${ }^{9}$ Huainan Mining Industry (Group) Co., Ltd., Huainan, Anhui 232001, China \\ ${ }^{10}$ Xinjiang Tianchi Energy Co., Ltd., Changji 831100, China
}

Correspondence should be addressed to Xianjie Hao; haoxianjie@cumtb.edu.cn

Received 11 February 2019; Accepted 7 April 2019; Published 2 May 2019

Academic Editor: Constantin Chalioris

Copyright (c) 2019 Xianjie Hao et al. This is an open access article distributed under the Creative Commons Attribution License, which permits unrestricted use, distribution, and reproduction in any medium, provided the original work is properly cited.

\begin{abstract}
The process of crack propagation and tunnel failure is affected by the cross-sectional geometry of an underground tunnel. In order to quantify the effect of section shape on the process of crack propagation in deep tunnels under high ground stress conditions, a total of four physical models with two cross-sectional shapes and twelve stress levels were designed and several large-scale physical model tests were conducted. The results indicated that, when the vertical stress is $4.94 \mathrm{MPa}$, the length and depth of the cracks generated in the rock surrounding the horseshoe tunnel are about eight times that around a circular tunnel. The position where the circumferential displacement of the horseshoe tunnel begins to be stable is about two, to two and a half, times that around a circular tunnel. After the deep chamber was excavated, continuous spalling was found to occur at the foot of the horseshoe tunnel and microcracks in the surrounding rock were initially generated from the foot of the side wall and then developed upwards to form a conjugate sliding shape to the foot of the arch roof, where the cracks finally coalesced. Discontinuous spalling occurred at the midheight of the side wall of the circular tunnel after excavation, and microcracks in the surrounding rock were initially generated from the midheight of the side wall and then extended concentrically to greater depth in the rock mass surrounding the tunnel. Tensile failure mainly occurred on the surface of the side wall: shear failure mainly appeared in the surrounding rock.
\end{abstract}

\section{Introduction}

The process of crack propagation in the surrounding rock is significant to the excavation and supports of an underground mine. The process of crack propagation is essential to study the failure mechanism of materials in different underground environments. Furthermore, coal mining has gradually developed to increased depths: mines at depths of $1000 \mathrm{~m}$ are not uncommon. Therefore, a study of the process of tunnel stability and cracking propagation of ultradeep mines is worthwhile [1]. 
There are many factors affecting the process of crack propagation and tunnel failure, and the cross section of the tunnel is one of the most important such factors. Presently, common section shapes of the underground tunnel include arched sections, circular sections, rectangular sections, and trapezoidal sections. Among them, tunnels with arched sections and circular sections are most widely used. Underground tunnels with arched sections are mainly used for haulage roadways in mining districts, rocky main roadways, and gathering main roadways in coal mines. Underground tunnels with circular sections are mainly applied in mines in soft rock, or in those under high in situ stress, and those subject to large deformations.

Many researchers have investigated the process of tunnel stability and crack propagation of an underground tunnel from the perspective of the cross-sectional shape of the tunnel. Mobaraki and Vaghefi [2] carried out a numerical study of the depth and cross-sectional shape of a tunnel under surface explosive loading. The Kobe box shape subway tunnel was used as an example in comparison with semiellipse-, circular-, and horseshoe-shaped tunnels. Lu et al. [3] analyzed the optimal shape of a tunnel that satisfies the optimization criterion by using the conformal mapping method for a plane elasticity complex function. Based on FLAC ${ }^{3 \mathrm{D}}$, Meng et al. [4] simulated the excavation of roadways with different cross sections, including rectangular, trapezoidal, straight wall arch, horseshoe, oval, and circular shapes, and the deformation characteristics of surrounding rock and the distribution of plastic zone of surrounding rock were explored. The plastic zone distribution and the differences between principal stress and the deformation of the rock surrounding six typical roadway types were simulated with FLAC $^{5.0}$ [5]. Based on the UDEC program, $\mathrm{Ma}$ et al. [6] carried out a series of numerical simulations for roadways with five different cross sections to analyze the energy release characteristics and distribution of stress and plastic zones in the surrounding rock and reveal the influence of horizontal tectonic stress. Xu et al. [7] proposed a rock burst energy release rate (RBERR) criterion, and the evolution of rock damage and failure of advancing excavation faces with different cross sections were simulated: however, most of these studies into the influence of section shape on tunnel stability are qualitative, and there is a lack of quantitative analysis of the effects of section shape.

It is useful to analyze the process of instability and crack propagation of rock mass by large-scale physical model testing $[8,9]$. The process of crack propagation in the surrounding rock and the process of tunnel deformation and failure can be directly obtained through similarity simulation experiment. $\mathrm{Li}$ et al. [10] conducted a 3D physical model test to clarify the effect of the dipping formation and bidirectional excavation on the tunnel deformation: crown settlement, floor heave, and radial displacement of the equivalent sections in the physical model were investigated. Kiani et al. [11] carried out a series of centrifuge model tests on segmental tunnels subjected to normal faulting and the physical modelling of a normal fault, a segmental tunnel in a centrifuge, and the results of nine centrifuge tests were described. Li et al. [12] performed a large-scale geomechanical model test based on Zhaolou coal mine in China. The displacement and stress evolution laws of surrounding rock supported by the pressure relief anchor box beam system were elucidated. Lei et al. [13] designed an experimental programme and simulated the excavation of three asymmetrically loaded model tunnels with different bias angles to reveal the failure mechanism of both the lining and surrounding rock on shallow buried tunnels under asymmetrical load. Jiang et al. [14] explored the relationships among advancing direction, strata behaviors, and rock burst induction by establishing two physical models. Sun et al. [15] conducted an experimental study of the floor heave of roadway excavated in deep, inclined strata. Chen et al. [16] reported a series of smallscale physical tunnel model tests to represent the true behavior of a real tunnel under extreme loading. Fang et al. [17] demonstrated scale model tests in a $1 \mathrm{~g}$ gravitational field on a tunnel excavation undercrossing the caved zone of a goaf: settlement of the roof, floor of the caved zone, and vault settlement of the tunnel during excavation were tested and compared. The mechanical behavior of the rock strata during mining was simulated on the basis of a 2D physical model [18]. Huang et al. [19] explored the effect of a weak interlayer on failure patterns in a rock mass around a tunnel, both physical model tests and numerical analysis were carried out to simulate tunnel excavation near an interlayer. Li et al. [20] developed a new large-scale physical simulation method to investigate the deformation and failure modes of weak rocks surrounding a tunnel. Fu et al. [21] proposed a statistical model for predicting the triaxial compressive strength of transversely isotropic rocks subjected to freeze-thaw cycling. Guo et al. [22] elaborated the influence of blasting excavation of a new roadway on neighboring, preexisting roadways of different cross sections by using a digital laser dynamic caustics experimental system and conducting a simulation. Ma et al. [23] carried out a series of three-dimensional centrifuge model tests which were performed to examine the effects of side-byside twin tunneling at varying depths on an existing buried pipeline in dry sand.

In conclusion, it can be seen that there is a lack of research on the influence of section shape on deep tunnel stability by means of large-scale physical model tests.

In conclusion, it can be seen that there is a lack of research on the influence of section shape on deep tunnel stability by means of large-scale physical model tests. With increasing mining depth and the increasingly complex stress environment, the effect of stress magnitude and loading rate on the stability of tunnels with different cross-sectional shapes is worthy of comparative study. So, it is a question whether the positive effect of the cross-sectional shape on the stability of the tunnel remains unchanged in different stress environments or not. Thus, this research quantifies the effects of section shape on the process of crack propagation and tunnel failure, by examining stress redistribution, displacement, geometric characteristics (such as length and depth) and their effects on the crack propagation, and development of damage. 
In this paper, four physical models with two section shapes and twelve stress levels were designed and several large-scale physical model tests were carried out to quantify the effect of cross section on the process of crack propagation and tunnel failure of a deep tunnel under high ground stress conditions. In Section 2, the ability of experimental instruments was introduced. In Section 3, the material parameters and composition of the model for similar simulation experiments were determined and the test scheme of two kinds of cross sections and 12 load magnitudes were proposed. In Section 4, the experimental results of different cross sections and load magnitudes are introduced, including the process of displacement, the size of the damaged zone in the process of excavation, cracking expansion process, and failure mechanism. Based on the results of numerical and physical model simulation, the effect of the loading path on the process of crack propagation and tunnel failure of a deep tunnel with different crosssectional shapes are compared and analyzed in Section 5.

\section{Physical Test Equipment}

A simulation test system for failure process and mechanism of surrounding rock in deep engineering was used in this experiment. The system can be used to simulate threedirectional loading in high ground stress environments. The deviation of load concentration on the surface of the measured model is less than $1 \%$. The pressure applied to the model can be kept stable for more than 48 hours. The deep engineering geostress environment found with burial depths of around $1000 \mathrm{~m}$ can be simulated: it can be used to excavate the tunnel model in stages and perform anchorage simulations under conditions maintaining high ground stresses. The longitudinal load-bearing system (Figure 1) contained in the main body was used to control tunnel axial deformation. The hydraulic loading and control system are composed of a high-precision static servo-hydraulic control system (Figure 2). The dynamic load stabilization accuracy is $\pm 2 \%$, and the static load stabilization accuracy is $\pm 0.5 \%$. Visual operation can be implemented in the data acquisition system (Figure 3). The radial strain and the circumferential strain in the surrounding rock and the deformation process of the model tunnel can thus be shown.

\section{Physical Test Schedules}

3.1. Similarity Principles. To study the failure process of tunnels by using physical model tests, the physical models must satisfy a set of similarity criterion, including geometric similarity, physical and mechanical properties similarity, boundary conditions, and initial state. According to similarity theory and dimensional analysis, these similarity conditions can be acquired by establishing the force balance equation, geometric analysis, Hooke's law, and boundary conditions. The similarity between physical models and prototypes is defined as follows:

$$
K_{i}=\frac{i_{\mathrm{m}}}{i_{\mathrm{p}}}
$$

The physical parameters of the model and prototype are expressed by $i_{\mathrm{m}}$ and $i_{\mathrm{p}}$, respectively. The relevant physical parameters are listed in Table 1.

3.2. Size of the Experimental Model. Because of the size of the tunnel being $3 \mathrm{~m}$, according to the similarity ratio, the diameter of the model chamber is $200 \mathrm{~mm}$. Considering that when the model is five times the size of the tunnel, the effect of the boundary conditions on the tunnel is such that it reduced the effect of the boundary conditions on the tunnel. Therefore, the size of the physical model was determined to be (length by width by thickness) $1,000 \times 1,000 \times 400 \mathrm{~mm}$. The axial direction perpendicular to the roadway is the plane strain section. The geometrical dimensions of the model and the tunnel of the horseshoe tunnel and the circular tunnel are illustrated in Figure 4.

3.3. Composition. According to several experiments, a kind of low-grade cement mortar with the weight ratio of cement : sand: water of $1: 14: 1.4$ was selected as the simulated rock material. The physical model was formed by ramming-type compaction. All relevant physical parameters were selected as listed in Table 2. The similarity ratio of each parameter is the same as that in Table 1.

3.4. Measurement Techniques. The layout of monitoring lines is an important aspect of monitoring the whole process of tunnel failure. According to the field observation, the middle of the model tunnel is the most damaged and the strain is the largest. Therefore, 11 measurement points were arranged in the middle of the left wall of the model tunnel. While building the physical model, strain gauges and an electrical resistance grid technique were placed in the rock surrounding the tunnel to monitor the whole process of tunnel failure. Two strain gauges were arranged at each measuring point (specification: $2 \times 15 \mathrm{~mm}$ colloidal strain gauge). One of the strain gauges measures the strain in the radial direction, and the other measures the strain in the circumferential direction. In order to monitor the strain at cracking process, the spacing of the strain gauges arranged near the wall is small (Figure 5). To monitor the process of crack propagation, an electrical resistance grid technique was arranged at the midheight of the side wall and the middle of the roof. The length of the electrical resistance grid is $100 \mathrm{~mm}$. As shown in Figure 6, the 21 contacts were placed on the electrical resistance grid. The distance between each contact point is $5 \mathrm{~mm}$, and each contact was connected to the lead wire through a $2 \mathrm{~mm} \times 3 \mathrm{~mm}$ terminal. Each of the two adjacent lead wires was connected to an LED. When a crack was not generated, the electrical resistance grid was not broken, and the LED was not short circuited. After tunnel cracking was generated, the electrical resistance grid was broken in the corresponding position(s) and the 


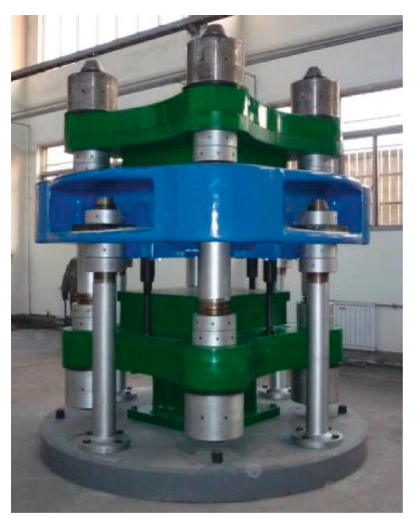

(a)

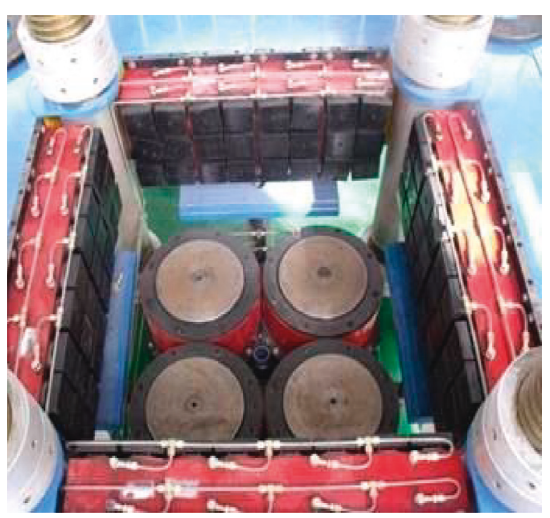

(b)

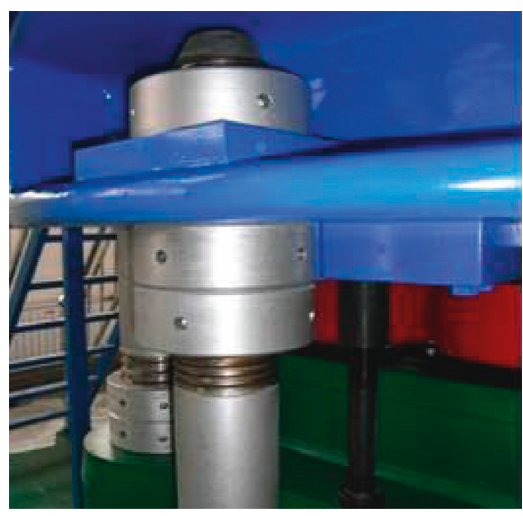

(c)

FIGURE 1: The main equipment used in the test system to monitor crack propagation and tunnel failure. (a) Key equipment. (b) Loading system. (c) The bearing system.

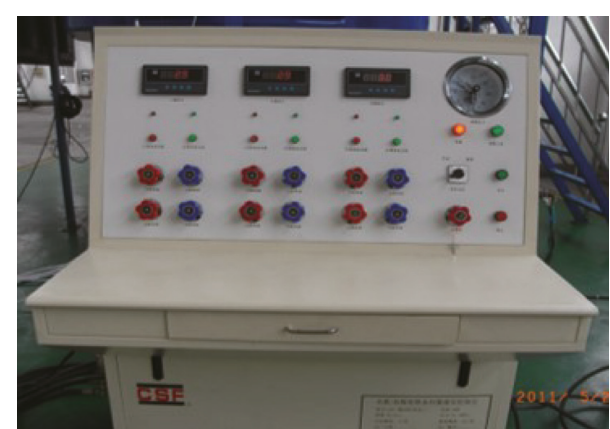

FIgURE 2: High-precision static servo-hydraulic control system.

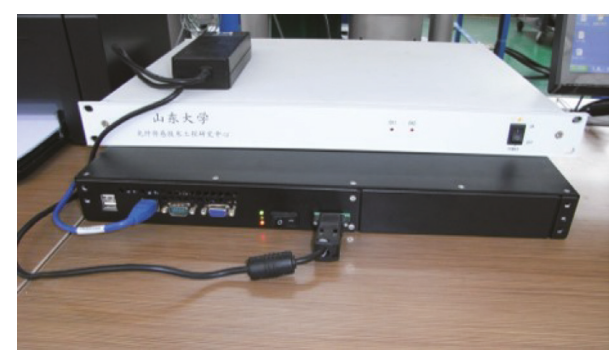

Figure 3: Data acquisition and the actual system modelled.

LED illuminates. Therefore, the process of crack propagation could be monitored by LED illumination sequences.

3.5. Test Scheme. To investigate the effect of section shape on the tunnel failure process, four groups of models, two section shapes, and 12 load magnitudes were tested on T1, T2, T3, and T4, respectively. Specific test schemes are displayed in Table 3 . The stress radio of model tests is $1: 20$. According to the calculation, when the loading of the model exceeds $2.3 \mathrm{MPa}$, the simulated depth has reached $1000 \mathrm{~m}$; therefore, the underground tunnel at this depth is simulated herein.

\section{Test Results: Tunnel Failure Process}

4.1. Determination of Crack Propagation Patterns and Tunnel Failure. During testing, the electrical resistance grid technique used in the physical model recorded the process of crack propagation in the surrounding rock. Since the physical model is a plane strain model, the process of displacement and failure of each section is the same along the length of the tunnel; therefore, photographs taken during these experiments can also help us to judge the depth and degree of tunnel failure. Combined with the data from the electrical resistance grid technique and the results of the camera footage, the process of crack propagation in the rock surrounding the tunnel under different loading conditions can be obtained.

The Fast Lagrangian Analysis of Continua in 3 Dimensions (FLAC3D) was used for numerical simulation, and the results were compared with the experimental results. The size of the three-dimensional numerical model of the Horseshoe tunnel is shown in Figure 7. The size of the threedimensional numerical model of the circular tunnel is demonstrated in Figure 8. The methods of mesh generation for the fine division near the excavation tunnel and coarser division at the boundary are adopted. There are 45,143 zones and 38,509 grid points in the horseshoe tunnel mode. There are 32,246 zones and 33,801 grid points in the circular tunnel mode. The Mohr-Coulomb constitutive model with a tension cutoff was employed with a finite difference approach. The mechanical parameters of this model are shown in the second row of Table 2.

Here, an index called FAI (failure approach index) was used to estimate the extent of failure of the rock mass [24]. According to the method provided by Feng et al. [25], the depth of the through failure in the surrounding rock of the tunnel was inverted, which proves that the use of FAI is feasible. Field measurements and numerical simulations of tunnel $\mathrm{T} 1$, when loaded to $6.30 \mathrm{MPa}$, are shown in Figure 9(a). It can be seen that under the current parameters, the shape of the contour for FAI $=4$ is similar to the shape of the crack: when the stress on tunnel T2 reached $5.63 \mathrm{MPa}$, as shown in Figure 9(b), at $\mathrm{FAI}=4$, the longest distance 
TABLE 1: The principle of determining physical model parameters.

\begin{tabular}{lccc}
\hline Category of parameter & Physical parameters & Similarity ratio equations & Remarks \\
\hline \multirow{4}{*}{ Geometric parameters } & Height, $H$ & $K_{H}=H_{\mathrm{m}} / H_{\mathrm{p}}$ & It is determined by using the geometric parameters of \\
& Span/radius, $R$ & $K_{R}=R_{\mathrm{m}} / R_{\mathrm{p}}$ & the field tunnel and the physical model, $K_{H}=K_{R}=1 /$ \\
Gravity parameter & Density, $\rho$ & $K_{\rho}=D_{\mathrm{m}} / D_{\rho}$ & For the same gravitational field, $K_{g}=1$ \\
& Gravitational acceleration, $g$ & $K_{g}=g_{\mathrm{m}} / g_{\mathrm{p}}$ & F \\
& Tensile strength, $R_{\mathrm{t}}$ & $K_{R_{\mathrm{t}}}=R_{\mathrm{t}_{\mathrm{m}}} / R_{\mathrm{t}_{\mathrm{p}}}$ & \\
Intensity parameter & Compressive strength, $R_{\mathrm{c}}$ & $K_{R_{\mathrm{c}}}=R_{\mathrm{c}_{\mathrm{m}}} / R_{\mathrm{c}_{\mathrm{p}}}$ & $K_{R_{\mathrm{t}}}=K_{R_{\mathrm{c}}}=K_{C}=K_{E}=K_{g} \times K_{l} \times K_{\rho}=1 / 20$ \\
& Cohesion, $C$ & $K_{\mathrm{C}}=C_{\mathrm{m}} / C_{\mathrm{p}}$ & $K_{\mu}=K_{\varphi}=1$ \\
& Internal friction angle, $\varphi$ & $K_{\varphi}=\varphi_{\mathrm{m}} / \varphi_{\mathrm{p}}$ & \\
Deformation parameters & Poisson's ratio, $\mu$ & $K_{\mu}=\mu_{\mathrm{m}} / \mu_{\mathrm{p}}$ & \\
& Elasticity modulus, $E$ & $K_{E}=E_{\mathrm{m}} / E_{\mathrm{p}}$ & \\
& &
\end{tabular}

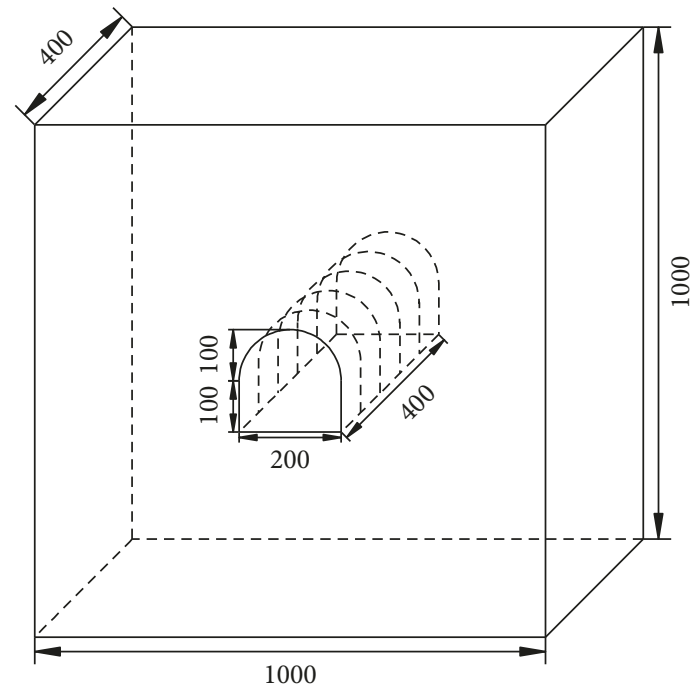

(a)

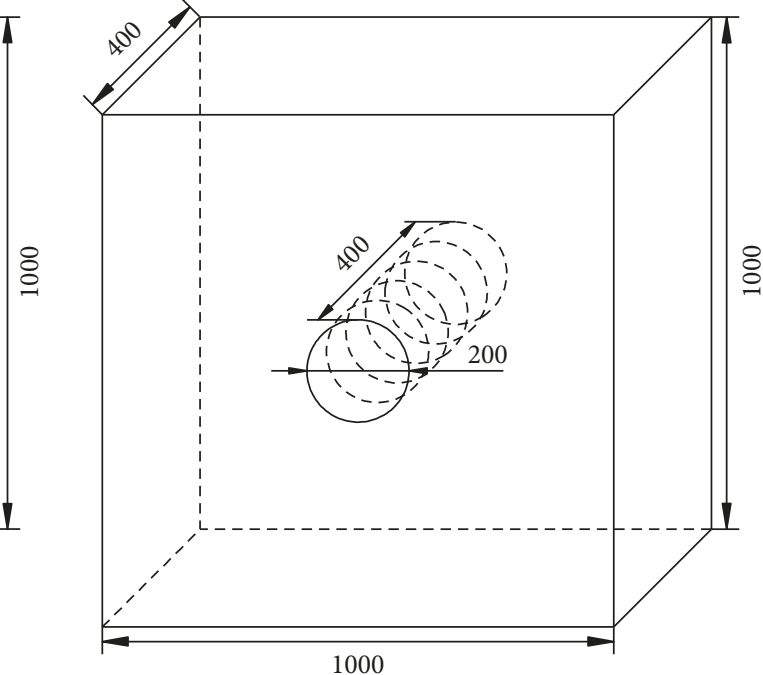

(b)

Figure 4: Model used in physical model tests. (a) Horseshoe tunnel. (b) Circular tunnel.

TABLE 2: The principle of determining physical model parameters.

\begin{tabular}{|c|c|c|c|c|c|c|c|}
\hline Parameters & $\begin{array}{c}\text { Compressive } \\
\text { strength, } R_{\mathrm{c}} \\
(\mathrm{MPa})\end{array}$ & $\begin{array}{c}\text { Tensile } \\
\text { strength, } \\
R_{\mathrm{t}}(\mathrm{MPa})\end{array}$ & $\begin{array}{c}\text { Cohesion, } \\
C(\mathrm{MPa})\end{array}$ & $\begin{array}{c}\text { Internal } \\
\text { friction } \\
\text { angle, } \varphi\left({ }^{\circ}\right) \\
\end{array}$ & $\begin{array}{c}\text { Modulus of } \\
\text { elasticity, } E \\
(\mathrm{GPa})\end{array}$ & $\begin{array}{c}\text { Poisson's } \\
\text { ratio, } \mu\end{array}$ & $\begin{array}{c}\text { Density, } \\
\rho \\
\left(\mathrm{kg} / \mathrm{m}^{3}\right)\end{array}$ \\
\hline Prototype & 40 & 2.7 & 2.0 & 50 & 20 & 0.25 & 2400 \\
\hline Similarity ratios & 0.0528 & 0.0528 & 0.0528 & 1 & 0.0528 & 1 & 0.792 \\
\hline $\begin{array}{l}\text { Theoretical parameters of the } \\
\text { model }\end{array}$ & 2.0 & 0.14 & 0.1 & 50 & 1.0 & 0.25 & 1800 \\
\hline Actual parameters of the model & 2.28 & 0.3 & 0.8 & 54 & 0.63 & 0.25 & 1800 \\
\hline
\end{tabular}

between the isoline and the side wall is found to match the depth of cracks in the rock surrounding the tunnel. Therefore, the FAI $=4$ contour can be regarded as the farthest through crack through the side wall of the tunnel.

As load is applied, the failure process was recorded by using a high-definition camera and the electrical resistance grid technique. Since the established geological model is a plane strain model, the displacement generated in the model tunnel can be regarded as a two-dimensional problem. Therefore, the length of cracks could be calculated. The greatest displacement between the cracking and the side wall of the tunnel could be measured with reference to the copied crack image, which shows the crack depth under different loads. As a result, the process of macrocrack propagation is shown in Figure 10. The length and depth of cracking during each stage of excavation or loading are listed in Table 4 . The corresponding depth and total crack length are summarized in Table 4. The displacement characteristics of the side wall of the deformation process under the initial and maximum pressures are illustrated in Figure 11.

4.2. Process of Stress Redistribution. The numerical simulation results of the process of the maximum principal 


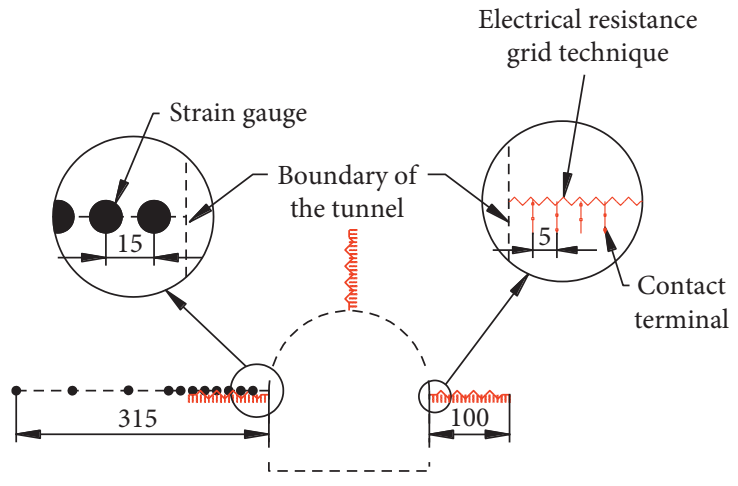

(a)

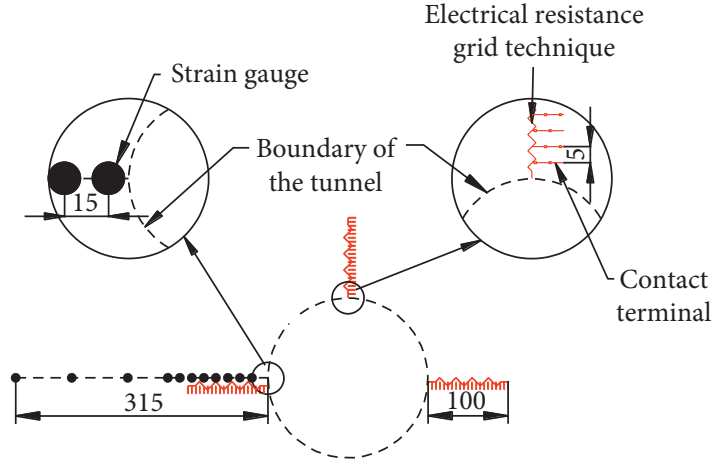

(b)

FIGURE 5: Strain gauge layout and the electrical resistance grid technique in the model. (a) Horseshoe tunnel. (b) Circular tunnel.

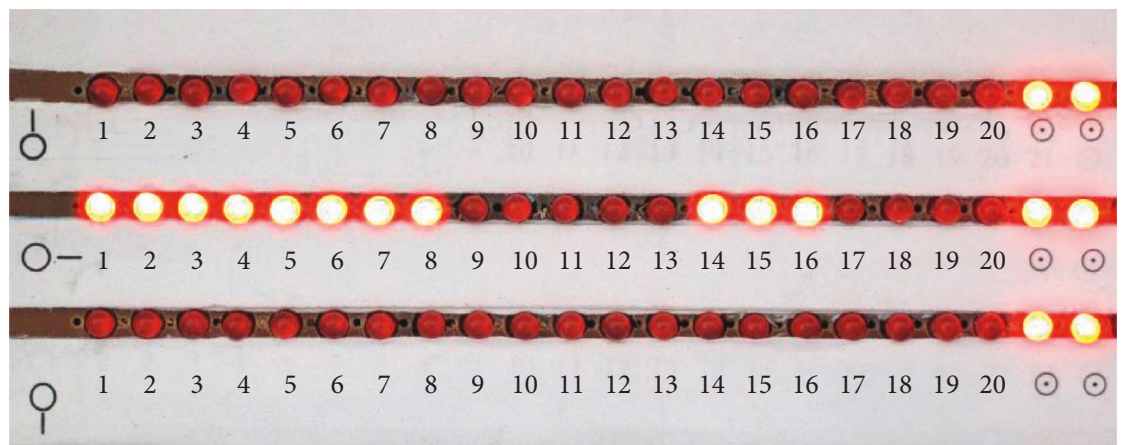

FIGURE 6: A working result from the electrical resistance grid technique.

TABLE 3: The loading plan for physical experiments.

\begin{tabular}{|c|c|c|c|c|c|c|}
\hline Number & $\begin{array}{c}\text { Section } \\
\text { shape }\end{array}$ & Loading (MPa) & $\begin{array}{c}\text { Initial } \\
\text { load }\end{array}$ & $\begin{array}{c}\text { Maximum } \\
\text { load }(\mathrm{MPa})\end{array}$ & Loading method & Excavation pattern \\
\hline $\mathrm{T} 1$ & Horseshoe & $\begin{array}{r}4.94 \\
5.40 \\
5.52 \\
6.06 \\
6.30\end{array}$ & $2.17 R_{\mathrm{C}}$ & $2.77 R_{\mathrm{C}}$ & & \\
\hline $\mathrm{T} 2$ & Circular & $\begin{array}{l}4.94 \\
5.43 \\
5.50 \\
5.56 \\
5.84\end{array}$ & $2.17 R_{\mathrm{C}}$ & $2.56 R_{\mathrm{C}}$ & $\begin{array}{l}\text { After excavation, the load is } \\
\text { applied to the maximum load step } \\
\text { by step, and the load is } \\
\text { maintained at } 10 \text { min for each }\end{array}$ & $\begin{array}{l}\text { The whole section of the tunnel is } \\
\text { excavated. Completed in four } \\
\text { steps. Each excavation is of }\end{array}$ \\
\hline Number & $\begin{array}{l}\text { Section } \\
\text { shape }\end{array}$ & $\begin{array}{l}\text { Pressure stability } \\
\text { time (min) }\end{array}$ & $\begin{array}{l}\text { Initial } \\
\text { load }\end{array}$ & $\begin{array}{c}\text { Maximum } \\
\text { load }(\mathrm{MPa})\end{array}$ & stage & 100 mm. Speedy driving. \\
\hline T3 & Horseshoe & $\begin{array}{c}8 \\
18 \\
4\end{array}$ & $2.47 R_{\mathrm{C}}$ & $2.47 R_{\mathrm{C}}$ & & \\
\hline $\mathrm{T} 4$ & Circular & $\begin{array}{c}23 \\
240\end{array}$ & $2.35 R_{\mathrm{C}}$ & $2.35 R_{\mathrm{C}}$ & & \\
\hline
\end{tabular}

$R_{\mathrm{c}}$ is the uniaxial compressive strength of model material, $2.28 \mathrm{MPa}$.

stress distribution in the rock surrounding the deep tunnel are shown in Figure 12. It shows that there is a similar maximum principal stress distribution for the horseshoe tunnel and the circular tunnel under high in situ stresses. When the vertical stress is $6.30 \mathrm{MPa}$, the maximum principal stress distributed in the rock surrounding the deep tunnel is compressive. For the rock surrounding the tunnel, the compressive stress increases to the in situ stress as the distance from the center of the tunnel increases. Therefore, the surrounding rock can be mainly divided into a stress-decreasing zone, stressincreasing zone, and an in situ stress zone accordingly. 


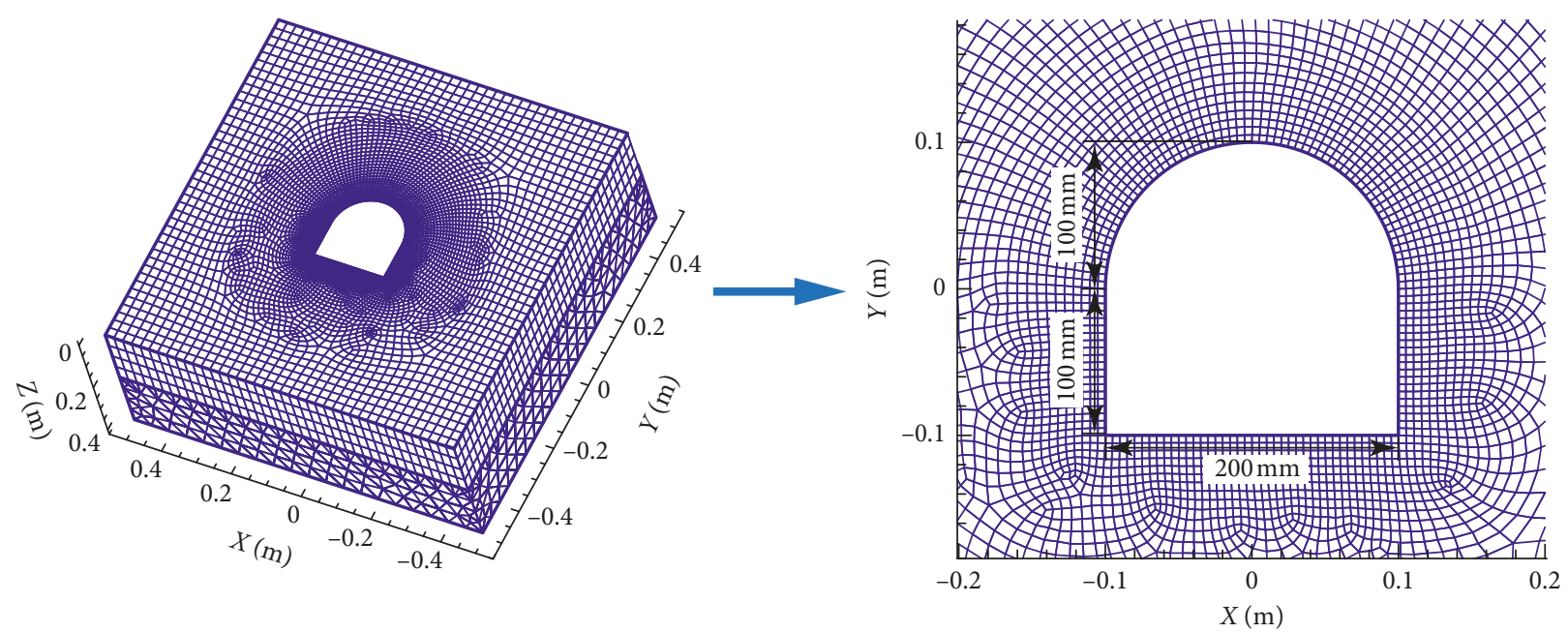

Figure 7: Numerical grid used to model the horseshoe tunnel.
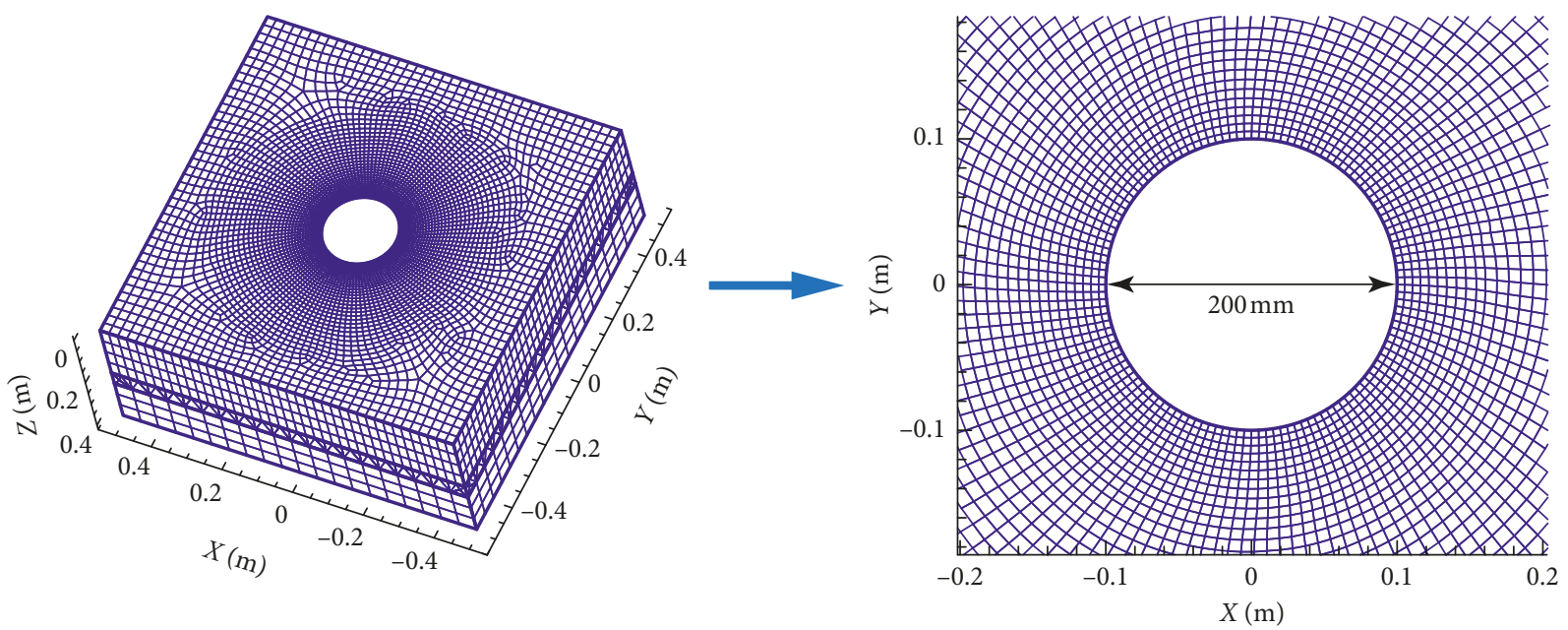

FIGURE 8: Numerical grid used to model the circular tunnel.

Compared with the side wall and the roof of the tunnel, the stress reduction effect of the tunnel floor is more obvious.

In this paper, the position at which the stress in the surrounding rock exceeds $5 \%$ of the in situ stress is seen as the boundary of the in situ stress zone. For the horseshoe tunnel $\mathrm{T} 1$, the in situ stress zone in the side wall is located at 1.5 times the diameter of the tunnel away from the tunnel boundary when the stress is $6.30 \mathrm{MPa}$. For circular tunnel $\mathrm{T} 2$, the in situ stress zone in the side wall is located at 1.4 times the diameter of the tunnel away from the tunnel boundary when the stress is $6.30 \mathrm{MPa}$. In the stressincreasing zone of the surrounding rock mass, the stress concentration factors of the two tunnels with different cross sections are both about 2.06. For tunnel T1, the maximum principal stress in the side wall is located at $61 \mathrm{~mm}(0.31 R)$ away from the boundary of tunnel. While for tunnel T2, the maximum principal stress in the side wall is located at $35 \mathrm{~mm}(0.18 R)$ away from the boundary of tunnel. The comparison suggests that the range of the mining disturbed zone of the tunnel T2 is smaller than that of the tunnel T1. The stress concentration factor of the tunnel $\mathrm{T} 1$ at the foot of the side wall is more obvious than that of the tunnel T2. This could explain the fact that, in the physical model experiment, the tunnel T1 was first damaged at the foot of the side wall under high in situ stresses (Figure 13), while the tunnel T2 suffered $\mathrm{V}$-shaped damage at the midheight of the side wall.

The tensile stress distributed in the surrounding rock of the deep tunnel in high in situ stress conditions can be visualized from the minimum principal stress contour map obtained from numerical simulation (Figure 14). When the vertical stress is $6.30 \mathrm{MPa}$, the tensile stress distributed in the rock surrounding the horseshoe tunnel $\mathrm{T} 1$ reaches $2.5 \mathrm{MPa}$. Under the same stress, there is no obvious tensile stress distribution in the rock surrounding tunnel T2, and only the minimum principal stress in part of the roof and floor of the tunnel is zero. This phenomenon shows that a small part of rock surrounding the circular tunnel T2 was damaged by tension. Therefore, combined with the redistribution of the maximum principal stress and the minimum principal 


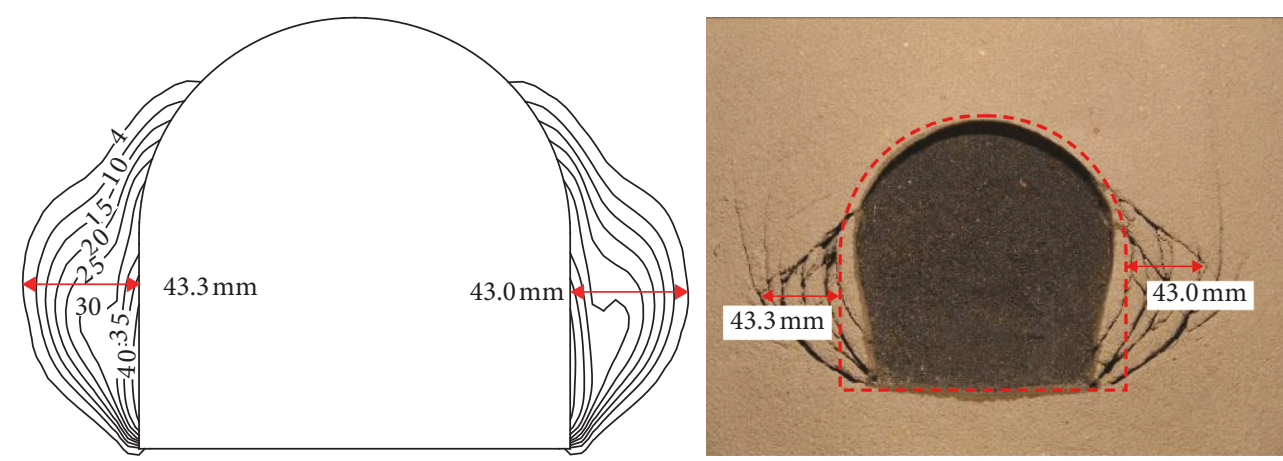

(a)
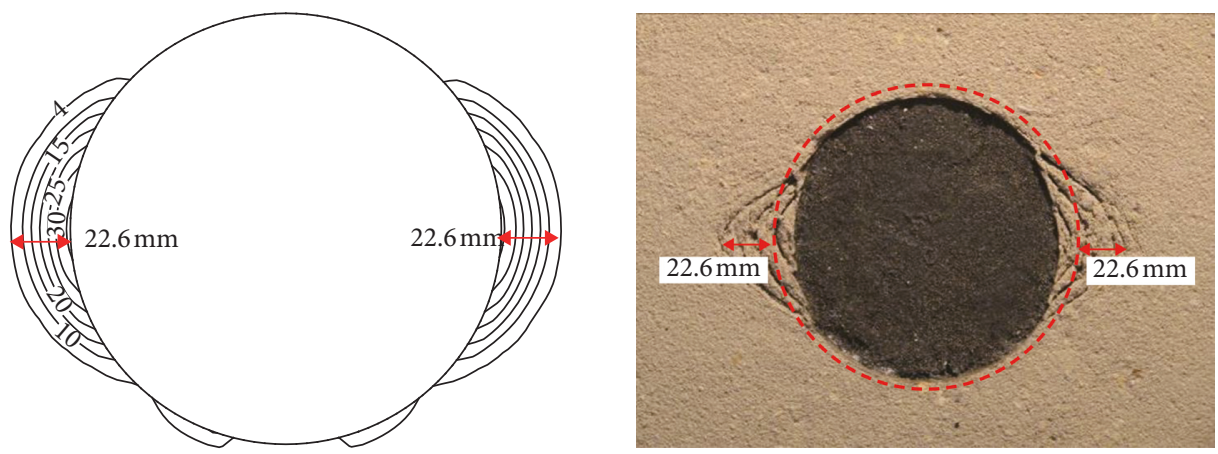

(b)

Figure 9: The result of the agreement between the contour line FAI $=4$ and the process of crack depth. The results of experimental and numerical simulation of (a) T1 under $6.30 \mathrm{MPa}$ and (b) T2 under $5.84 \mathrm{MPa}$.

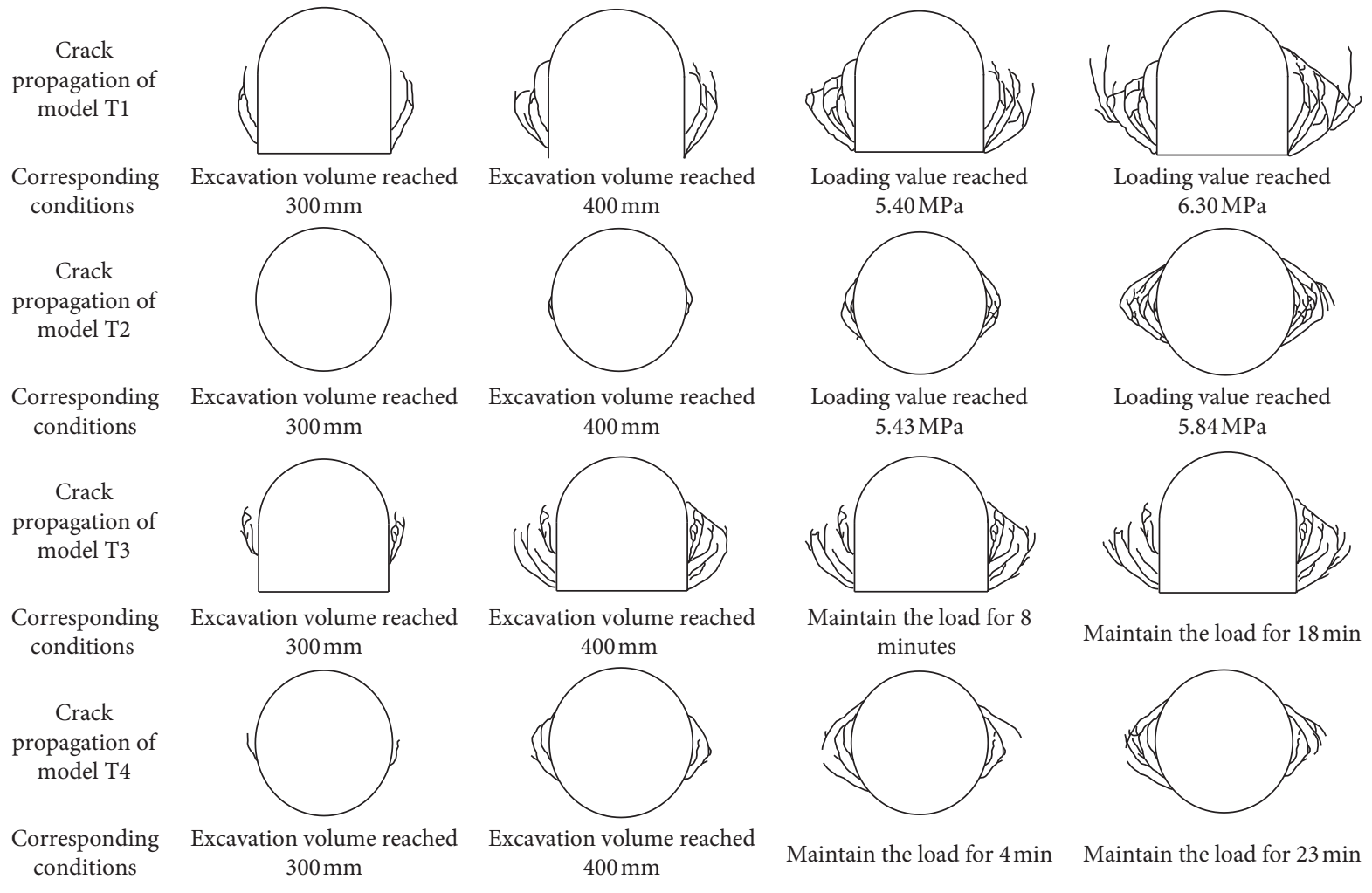

FIGURE 10: The process of macrocrack propagation around a tunnel during excavation, loading, and stabilization. 
TABLE 4: The depth and total length of cracks during tunnel excavation, loading, and stabilization.

\begin{tabular}{|c|c|c|c|c|c|c|c|c|c|c|c|}
\hline \multirow[t]{2}{*}{ 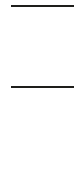 } & \multirow{2}{*}{$\begin{array}{c}\text { Initial } \\
\text { stress }\end{array}$} & \multicolumn{5}{|c|}{ The occurrence of cracks during excavation } & \multicolumn{5}{|c|}{ The occurrence of cracks during loading and stabilization } \\
\hline & & $\begin{array}{l}\text { Excavation } \\
\text { depth }(\mathrm{mm})\end{array}$ & $\begin{array}{c}\text { Left } \\
\text { depth } \\
(\mathrm{mm})\end{array}$ & $\begin{array}{c}\text { Left } \\
\text { length } \\
(\mathrm{mm})\end{array}$ & $\begin{array}{l}\text { Right } \\
\text { depth } \\
(\mathrm{mm})\end{array}$ & $\begin{array}{l}\text { Right } \\
\text { length } \\
(\mathrm{mm})\end{array}$ & Stress $(\mathrm{MPa})$ & $\begin{array}{c}\text { Left } \\
\text { depth } \\
(\mathrm{mm})\end{array}$ & $\begin{array}{l}\text { Left } \\
\text { length } \\
(\mathrm{mm})\end{array}$ & $\begin{array}{l}\text { Right } \\
\text { depth } \\
(\mathrm{mm})\end{array}$ & $\begin{array}{l}\text { Right } \\
\text { length } \\
(\mathrm{mm})\end{array}$ \\
\hline \multirow[t]{5}{*}{$\mathrm{T} 1$} & $4.94 \mathrm{MPa}$ & 100 & - & - & - & - & 5.4 & 57.6 & 600.3 & 52 & 569.7 \\
\hline & & 200 & - & - & - & - & 5.52 & 69.2 & 731.8 & 67 & 711 \\
\hline & & 300 & 24 & 206 & 28.1 & 181 & 6.06 & 91 & 932.1 & 83 & 950.9 \\
\hline & & 400 & 42.7 & 469.5 & 41 & 448.5 & 6.3 & 92 & 980.8 & 97 & 1011 \\
\hline & & $\begin{array}{l}\text { Excavation } \\
\text { depth }(\mathrm{mm})\end{array}$ & $\begin{array}{c}\text { Left } \\
\text { depth } \\
(\mathrm{mm})\end{array}$ & $\begin{array}{c}\text { Left } \\
\text { length } \\
(\mathrm{mm})\end{array}$ & $\begin{array}{l}\text { Right } \\
\text { depth } \\
(\mathrm{mm})\end{array}$ & $\begin{array}{l}\text { Right } \\
\text { length } \\
(\mathrm{mm})\end{array}$ & Load (MPa) & $\begin{array}{c}\text { Left } \\
\text { depth } \\
(\mathrm{mm})\end{array}$ & $\begin{array}{c}\text { Left } \\
\text { length } \\
(\mathrm{mm})\end{array}$ & $\begin{array}{l}\text { Right } \\
\text { depth } \\
(\mathrm{mm})\end{array}$ & $\begin{array}{l}\text { Right } \\
\text { length } \\
(\mathrm{mm})\end{array}$ \\
\hline \multirow[t]{5}{*}{$\mathrm{T} 2$} & $4.94 \mathrm{MPa}$ & 100 & - & - & - & - & 5.43 & 13.4 & 168.9 & 15.5 & 232.1 \\
\hline & & 200 & - & - & - & - & 5.50 & 18.2 & 211.7 & 22.9 & 300.9 \\
\hline & & 300 & - & - & - & - & 5.56 & 24.5 & 298.3 & 23.7 & 346.5 \\
\hline & & 400 & 3.4 & 43.8 & 7.2 & 58.8 & 5.84 & 39.5 & 550.4 & 44.3 & 616.4 \\
\hline & & $\begin{array}{l}\text { Excavation } \\
\text { depth }(\mathrm{mm})\end{array}$ & $\begin{array}{c}\text { Left } \\
\text { depth } \\
(\mathrm{mm})\end{array}$ & $\begin{array}{c}\text { Left } \\
\text { length } \\
(\mathrm{mm})\end{array}$ & $\begin{array}{l}\text { Right } \\
\text { depth } \\
(\mathrm{mm})\end{array}$ & $\begin{array}{l}\text { Right } \\
\text { length } \\
(\mathrm{mm})\end{array}$ & $\begin{array}{c}\text { Time of } \\
\text { stabilization } \\
(\min )\end{array}$ & $\begin{array}{c}\text { Left } \\
\text { depth } \\
(\mathrm{mm})\end{array}$ & $\begin{array}{c}\text { Left } \\
\text { length } \\
(\mathrm{mm})\end{array}$ & $\begin{array}{l}\text { Right } \\
\text { depth } \\
(\mathrm{mm})\end{array}$ & $\begin{array}{l}\text { Right } \\
\text { length } \\
(\mathrm{mm})\end{array}$ \\
\hline \multirow[t]{5}{*}{ T3 } & $5.63 \mathrm{MPa}$ & 100 & - & - & - & - & 8 & 65.6 & 633.3 & 63 & 660 \\
\hline & & 200 & - & - & - & - & 18 & 74.7 & 685.5 & 78 & 810.7 \\
\hline & & 300 & 28.5 & 192 & 20.9 & 202.7 & & & & & \\
\hline & & 400 & 64.7 & 590.2 & 58.5 & 621.6 & & & & & \\
\hline & & $\begin{array}{l}\text { Excavation } \\
\text { depth }(\mathrm{mm})\end{array}$ & $\begin{array}{c}\text { Left } \\
\text { depth } \\
(\mathrm{mm})\end{array}$ & $\begin{array}{c}\text { Left } \\
\text { length } \\
(\mathrm{mm})\end{array}$ & $\begin{array}{l}\text { Right } \\
\text { depth } \\
(\mathrm{mm})\end{array}$ & $\begin{array}{l}\text { Right } \\
\text { length } \\
(\mathrm{mm})\end{array}$ & $\begin{array}{c}\text { Time of } \\
\text { stabilization } \\
\text { (min) }\end{array}$ & $\begin{array}{l}\text { Left } \\
\text { depth } \\
(\mathrm{mm})\end{array}$ & $\begin{array}{l}\text { Left } \\
\text { length } \\
(\mathrm{mm})\end{array}$ & $\begin{array}{l}\text { Right } \\
\text { depth } \\
(\mathrm{mm})\end{array}$ & $\begin{array}{l}\text { Right } \\
\text { length } \\
(\mathrm{mm})\end{array}$ \\
\hline \multirow[t]{4}{*}{$\mathrm{T} 4$} & $5.36 \mathrm{MPa}$ & 100 & - & - & - & - & 4 & 39.31 & 351.6 & 44.76 & 252.3 \\
\hline & & 200 & - & - & - & - & 23 & 40.67 & 467.0 & 44.76 & 347.2 \\
\hline & & 300 & 10.2 & 41.3 & 9.5 & 40.9 & 240 & 40.67 & 501.6 & 44.76 & 390.0 \\
\hline & & 400 & 23.6 & 178.2 & 23.5 & 168.8 & & & & & \\
\hline
\end{tabular}

stress, the range of the mining disturbed zone and tensile failure zone of the circular tunnel T2 is smaller than that of the horseshoe tunnel T1.

\subsection{Progress of Cracking Depth and Extent}

4.3.1. Depth of Crack Propagation. The initial stress on the horseshoe tunnel $\mathrm{T} 1$ and the circular tunnel T2 is $4.94 \mathrm{MPa}$; however, after excavation, the rock surrounding the two tunnels with different cross sections underwent different processes of crack propagation. The process of cracking propagation can be seen in Figure 10 and Table 3. When the tunnel T1 was excavated to a depth of $300 \mathrm{~mm}$, cracks began to occur in the surrounding rock. At this time, the average crack depth on the left and right side walls is $26.05 \mathrm{~mm}$ $(0.13 \mathrm{R})$, and the average crack length is $193.5 \mathrm{~mm}$. When the tunnel T1 was excavated to a depth of $400 \mathrm{~mm}$, the average crack depth of the left and right side walls is $41.85 \mathrm{~mm}$ $(0.21 \mathrm{R})$, and the average crack length is $459.0 \mathrm{~mm}$. When the tunnel T2 was excavated to a depth of $300 \mathrm{~mm}$ under the same stress, there were no cracks formed in the surrounding rock. When the tunnel T2 was excavated to a depth of $400 \mathrm{~mm}$, the average crack depth in the left and right side walls is $5.3 \mathrm{~mm}(0.03 R)$, and the average crack length is $50.9 \mathrm{~mm}$. The comparison results demonstrate that the length and depth of cracks generated in the rock surrounding the horseshoe tunnel $\mathrm{T} 1$ are about eight times those in the circular tunnel T2 under the same stress. Therefore, when the tunnel was excavated and loaded under the same stress, the cracks generated in the horseshoe tunnel are longer and deeper than those in a circular tunnel.

4.3.2. Degree of Failure. Figure 15 shows progressive damage to the interior wall of the tunnel model after excavation in physical model tests. When tunnels with different sections were excavated under the same initial stress, in addition to the different processes governing the length and depth of cracks in the surrounding rock, the position of the point of failure on the inner wall also differed. It can be seen, from Figure 15, that the position of spalling failure of tunnel T1 is mainly concentrated at the foot of the side wall, while that in T2 is mainly concentrated at the midheight of the side wall, proving that the section of the underground tunnel influenced the position of failure therein: not only that, but the degree of damage to the interior walls of the two tunnels also varied with cross-sectional shape. Continuous spalling occurred at the foot of the horseshoe tunnel T1. Discontinuous spalling occurred at the midheight of the side wall of tunnel T2. The spalling depth of tunnel T1 was much larger than that of tunnel T2. As a result, when the tunnels with different cross-sectional shapes were excavated and loaded under the same stress, the damage to the inner wall of the horseshoe tunnel was more severe than that of the circular tunnel. 

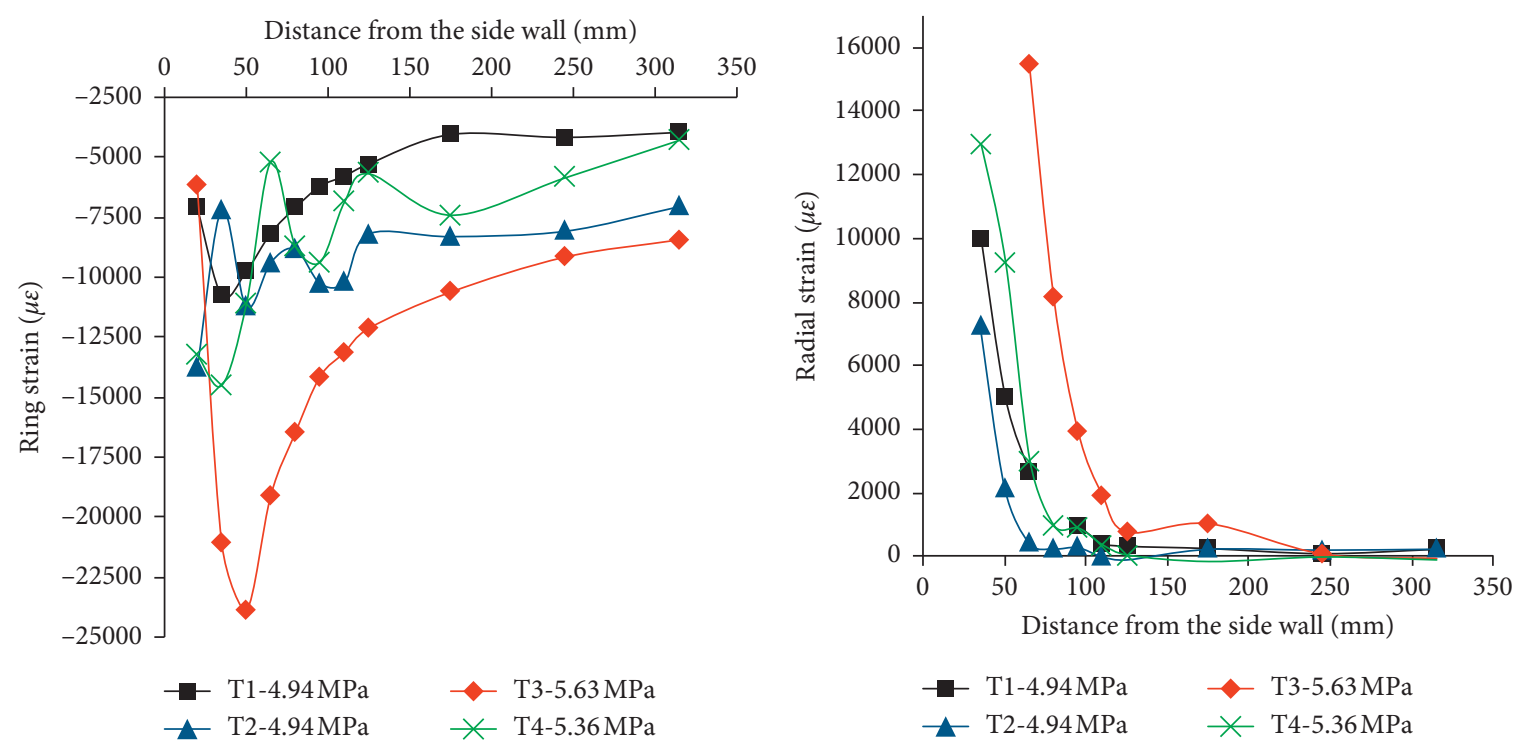

(a)

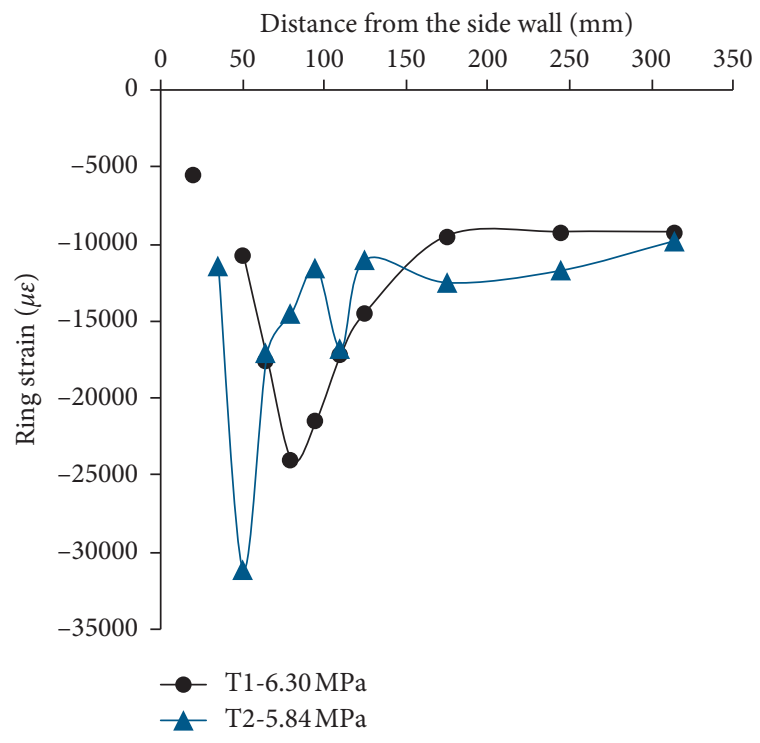

(b)

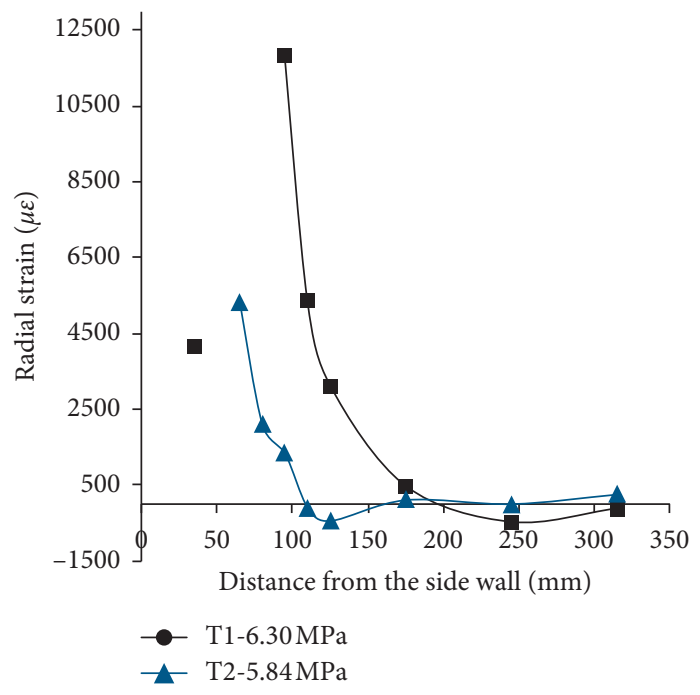

(c)

(d)

FIgURE 11: The strain in the surrounding rock mass during loading. (a) Ring strain at initial load. (b) Radial strain at initial load. (c) Ring strain at maximum load. (d) Radial strain at maximum load.

Combined with the distribution of FAI contours around tunnels $\mathrm{T} 1$ and $\mathrm{T} 2$, as obtained by numerical simulation (Figure 9) and the process of crack propagation in the physical model test (Figure 10), the evolution of crack propagation in the surrounding rock can be deduced. The contour line with the maximum value of FAI in the side wall of the horseshoe tunnel was initially generated from the foot of the side wall and then developed upwards in a conjugate sliding shape to the foot of the arch roof, where the crack finally coalesced. The contour line with the maximum value of FAI in the side wall of the circular tunnel initially generated from the midheight of the side wall, and then extended concentrically to the deep part of the rock surrounding the tunnel. The area enclosed by the FAI contour in tunnel $\mathrm{T} 1$ is much larger than that in tunnel T2, indicating a larger damage zone; therefore, there was a larger and deeper failure zone for a horseshoe tunnel under high in situ stress than that seen around a circular tunnel.

4.4. Progress of Displacement. When the tunnels are excavated under the same stress, the progress of displacement in the surrounding rock varied with the cross section of the tunnel: by comparing Figures 11(a) and 11(b), there are significant differences between a horseshoe tunnel and a circular tunnel in respect of the radial strain and circumferential strain generated in the surrounding rock. On the one hand, the shape and trend of the radial strain curves for tunnels $\mathrm{T} 1$ and $\mathrm{T} 2$ were similar. The axial strains in the rock surrounding $\mathrm{T} 1$ and $\mathrm{T} 2$ decreased rapidly with increasing 


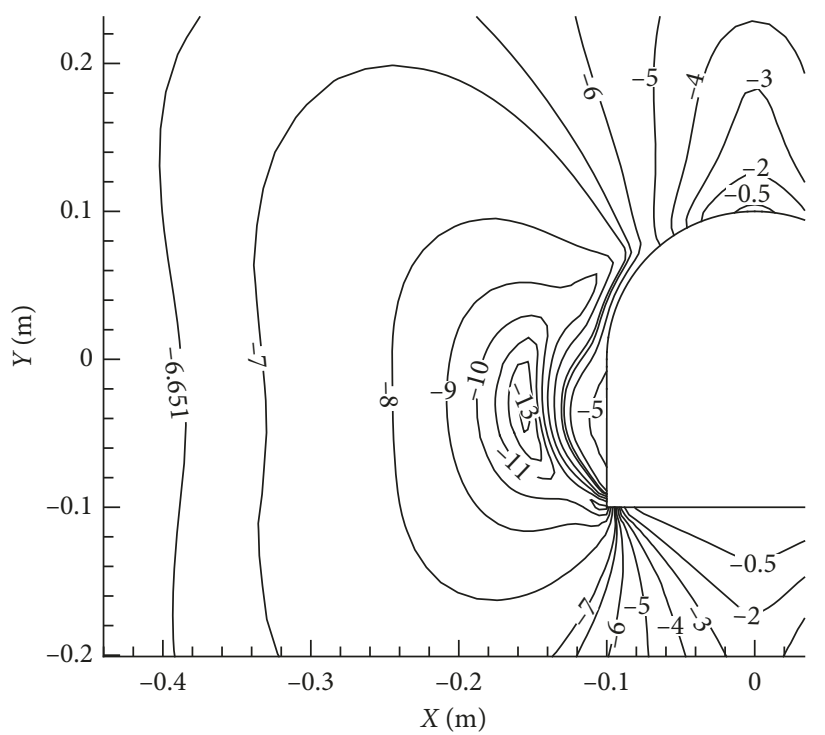

(a)

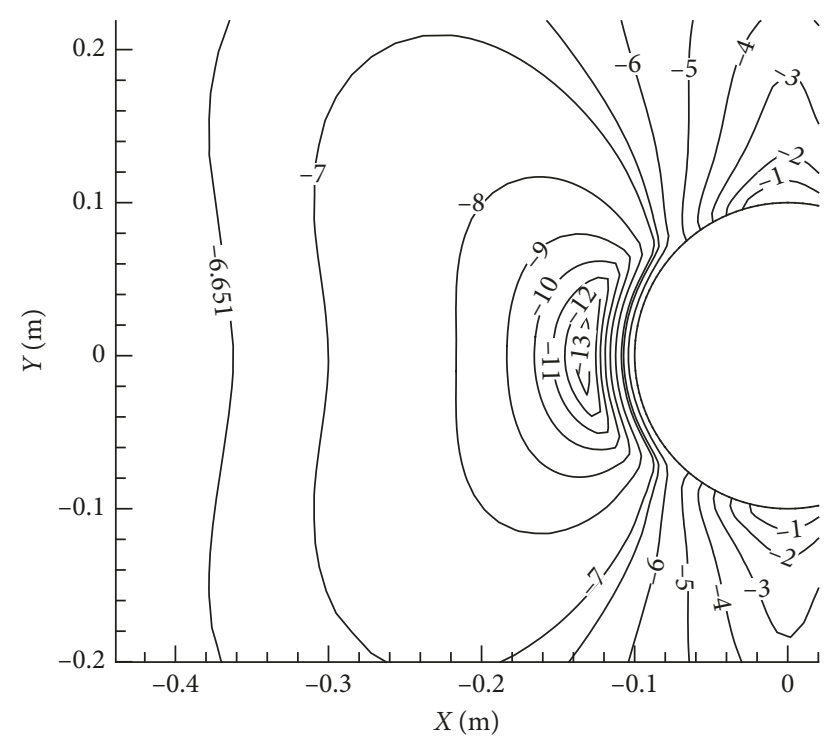

(b)

FIGURE 12: Numerical simulation results of the maximum principal stress in the rock surrounding deep tunnels. (a) Horseshoe tunnel. (b) Circular tunnel.

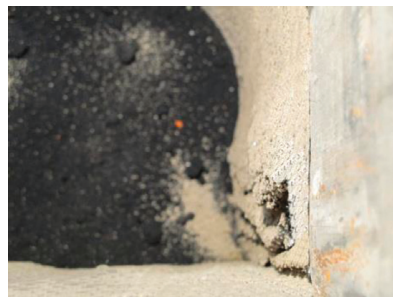

(a)

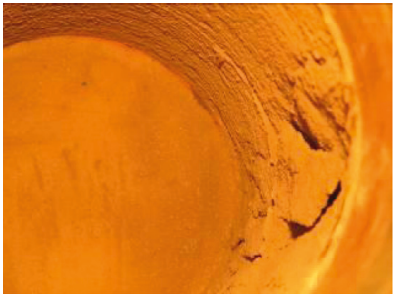

(b)

Figure 13: Destruction of the interior wall of tunnels with different cross sections under the maximum load in the physical model test. (a) Horseshoe tunnel T3: failure at the foot of the wall during pressure stabilization. (b) Circular tunnel T4: failure at the midheight of the side wall during pressure stabilization.

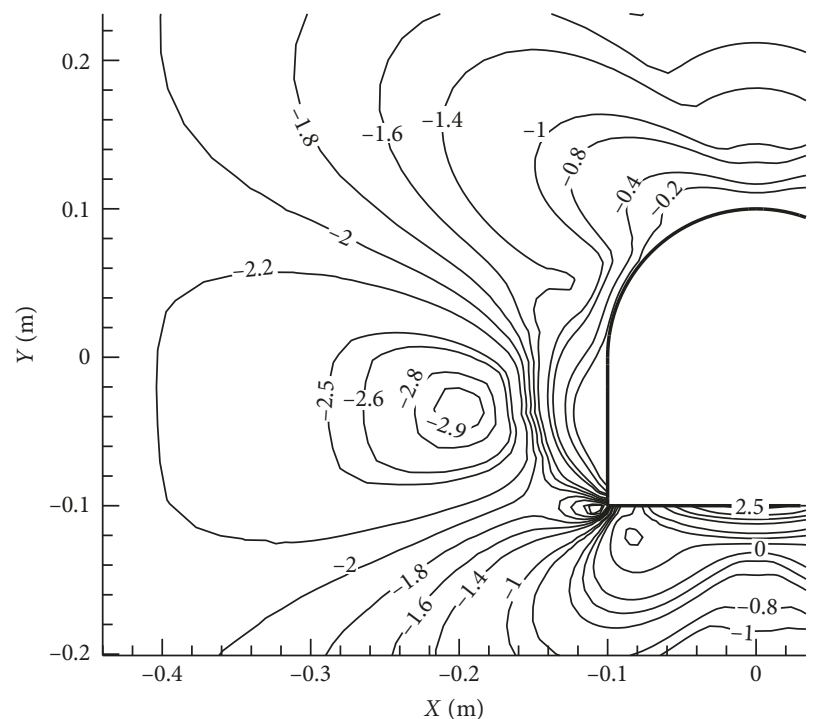

(a)

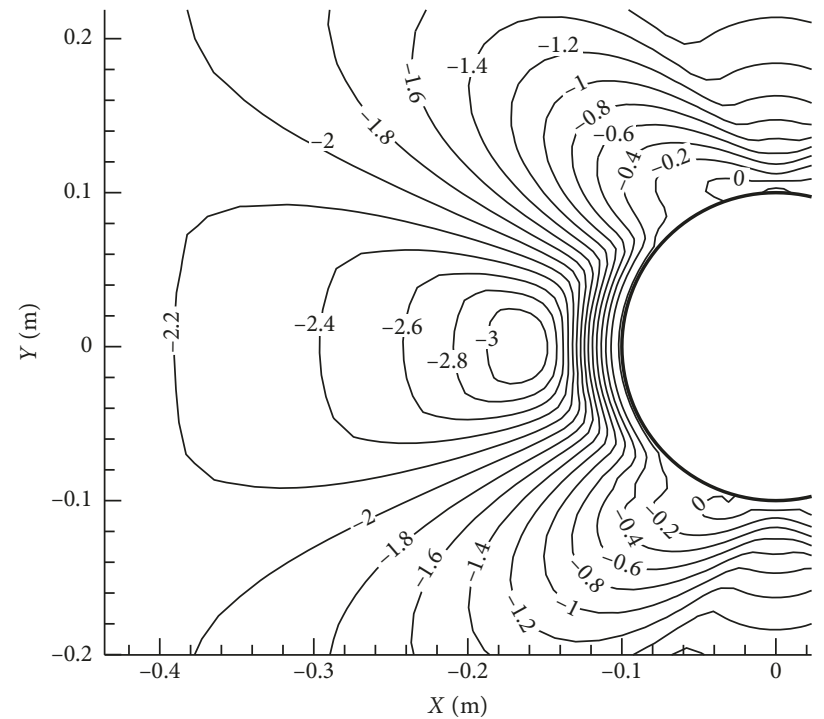

(b)

FIGURE 14: Numerical simulation results of the minimum principal stress in the rock surrounding the deep tunnel. (a) The horseshoe tunnel. (b) The circular tunnel. 


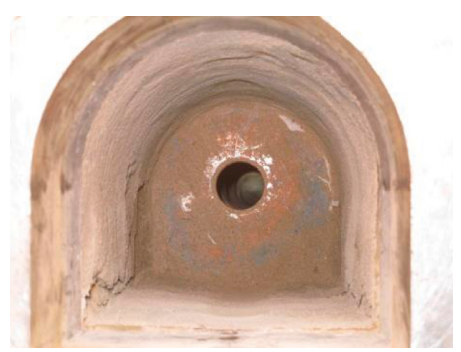

(a)

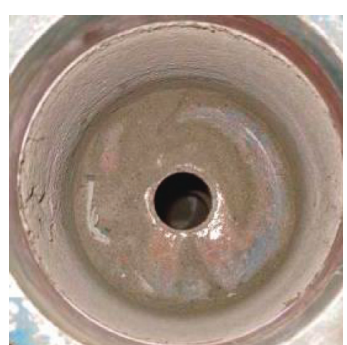

(b)

Figure 15: Destruction the interior wall of tunnels with different cross-sectional shapes after excavation in the physical model test. (a) The horseshoe tunnel. (b) The circular tunnel.

distance from the side wall boundary and both curves can be fitted by power function $y=a x^{b}$, where $b$ is a negative value which can reflect the rate of change of the curve. According to the fitting curve in Figure 16, the absolute value of $b$ for the radial strain curve of tunnel $\mathrm{T} 1$ is smaller than that of tunnel T2. This indicates that, when the radial strain in T2 tended to be stable, the distance corresponding to the side wall was closer than that in tunnel $\mathrm{T} 1$ which proves that the rock surrounding the circular tunnel was less affected by mining disturbance than in the horseshoe tunnel. It can be seen from Table 4 that the position where the radial displacement of tunnel T2 began to be stable was about $65 \mathrm{~mm}$ $(0.33 R)$ from the side wall. The position where the radial displacement of tunnel T1 started to be stable was about $110 \mathrm{~mm}(0.55 R)$ from the side wall, which was 1.69 times the distance in tunnel $\mathrm{T} 2$.

On the other hand, there is a significant difference in shape and extremum for the circumferential strain curves of tunnels T1 and T2 owing to their different sections. Figure 11(b) shows that the absolute value of the circumferential strain of the side wall of the horseshoe tunnel T1 first increased and then decreased; however, the circumferential strain curve for circular tunnel T2 fluctuated around a certain value and the fluctuation range of curve T2 gradually decreased with increasing distance from the side wall. In addition, the distance between the position where the circumferential displacement of the surrounding rock began to be stable and the side wall was different for tunnels of different shapes. When the stress was $4.94 \mathrm{MPa}$, the position where the circumferential displacement of tunnel T2 begins to be stable was about $125 \mathrm{~mm}(0.63 R)$ away from the side wall. The circular displacement of the tunnel T1 still decreased slowly at $245 \mathrm{~mm}(1.225 R)$ to $315 \mathrm{~mm}(1.575 R)$ from the side wall. Therefore, whether it was for radial strain or circumferential strain, the position where it tended to be stable in the circular tunnel was closer to the side wall than that in the horseshoe tunnel.

It can be seen from Figure 17 that, for the circumferential displacement of surrounding rock in the side wall of a deep tunnel, the conclusion obtained by numerical simulation was consistent with data from physical model tests. As the shape of the circular tunnel was symmetrical about the diametral axis, circumferential displacement in the rock surrounding the side wall was symmetrical along the

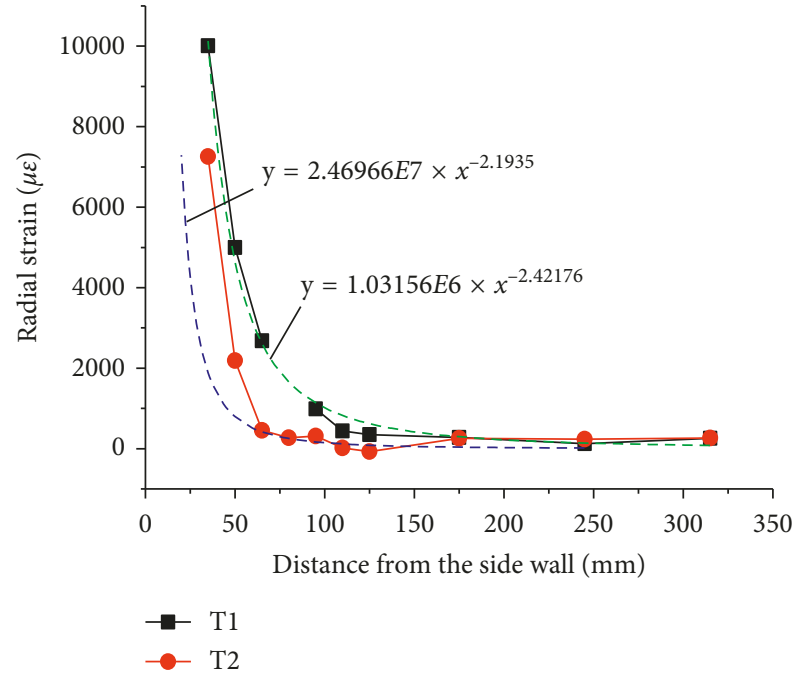

FIGURE 16: Relationship between radial displacement and distance from the side wall.

horizontal line under vertical, and horizontal, load. Therefore, the circumferential strain along the monitoring line in the physical model test fluctuated around zero, and the further from the side wall, the smaller the fluctuations. The fluctuations in circumferential strain gradually decreased with increasing distance from the side wall.

4.5. Mode of Failure. Figure 18 illustrates the distribution of plastic zones in the surrounding rock after the excavation of tunnels T1 and T2. It can be seen from Figures 12 and 18 that the distribution of the plastic zone is related to the redistribution process of maximum principal stress in the surrounding rock. The surrounding rock in the stressdecreasing zone was subjected to plastic failure. The plastic zone in the surrounding rock in a horseshoe tunnel and circular tunnel mainly occurred in the side wall. Tensile failure mainly occurred on the surface of the side wall. The shear failure mainly appeared in the surrounding rock. The area of tensile failure in the surrounding rock of a horseshoe tunnel was much larger than that around a circular tunnel. From the distribution of the plastic zone, it can be proved that the position of the deepest extent of damage of the horseshoe tunnel is at the $1 / 4$ height of the side wall, and the 


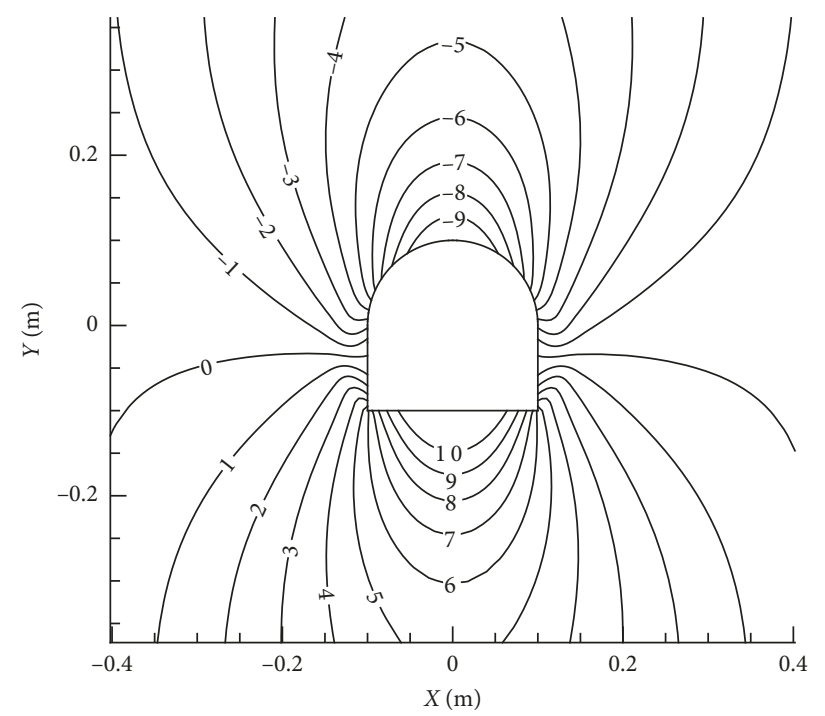

(a)

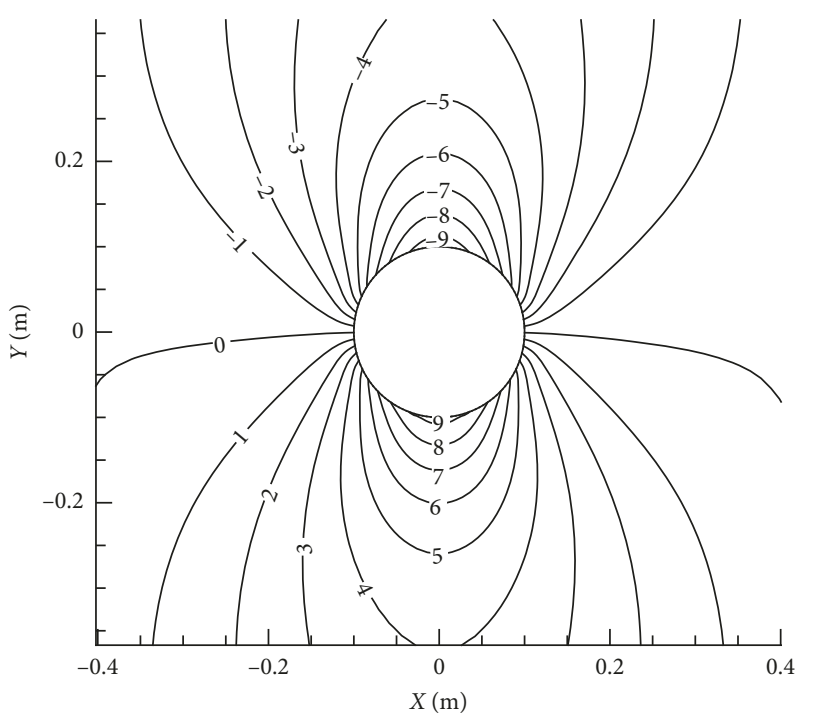

(b)

Figure 17: Numerical simulation results of the circumferential displacement in the rock surrounding the deep tunnel. (a) The horseshoe tunnel. (b) The circular tunnel.

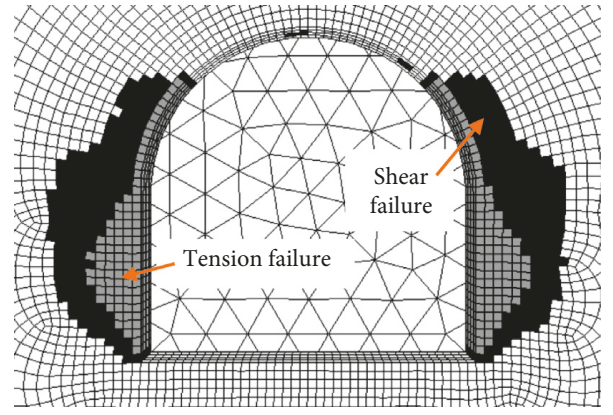

(a)

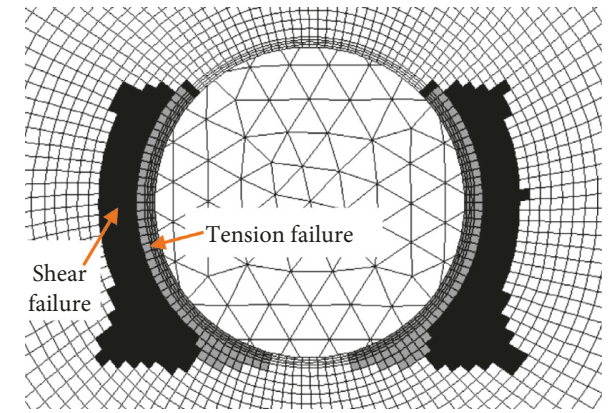

(b)

FIgURE 18: The distribution of the plastic zone in the surrounding rock after excavation. (a) The horseshoe tunnel. (b) The circular tunnel.

position of deepest damage to the circular tunnel is at the midheight of the side wall.

\section{Discussion}

For an underground tunnel, tunnel failure is affected by many factors, such as excavation near the tunnel and mining of the ore body. Under the disturbance of mining stress, the stress around the underground tunnel is bound to be redistributed. The changes in stress in the rock surrounding an underground chamber can be expressed by the loading path. The proposed loading path is of significance when quantifying the variation in stress and predicting the mechanical behavior of materials in different stress fields.

The increase of load will weaken the positive effect of the cross-sectional shape on the stability of tunnel, although the cross-sectional shape is still the most dominant factor affecting the stability of tunnel. By comparing the development of the average depth and average length of cracks in the surrounding rock of tunnels T1 and T2 (Figure 19), it can be found the depth and length of cracking process in both the horseshoe tunnel and the circular tunnel increased continuously with increasing stress. When the stress was 5.50 MPa, the rate of growth of crack depth and length in the side walls of the two tunnels reached their maximum. When the stress exceeded $5.50 \mathrm{MPa}$, there was no significant decrease, as was seen around tunnel T1, in the rate of growth of crack length and depth in tunnel T2. This is because, as the stress increased, the influence of the cross-sectional shape of a deep tunnel on its stability gradually decreased. As a result, the crack propagation around a circular tunnel tended to that of the horseshoe tunnel. Therefore, when the stress exceeded 5.50 MPa, the effect of the stress on tunnel stability was enhanced, and the effect of the section shape thereon decreased: however, it is undeniable that the length and depth of the cracks generated in the circular tunnel were lower than those in the horseshoe tunnel. When the circular tunnel was loaded to the maximum of $5.84 \mathrm{MPa}$, the crack length was 0.7 times that of the horseshoe tunnel under the same stress, and the crack depth was 0.5 times that of the straight-wall-top-arch tunnel under the same stress. 

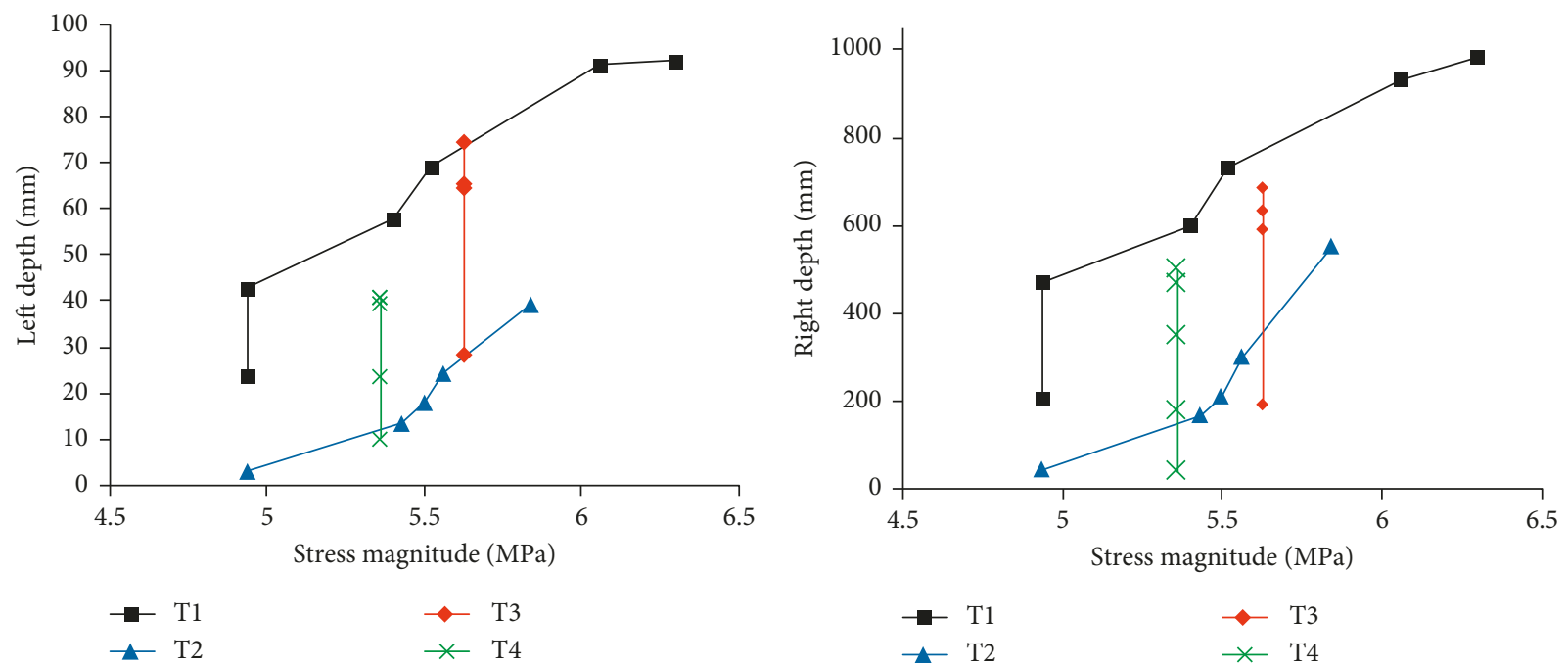

(a)
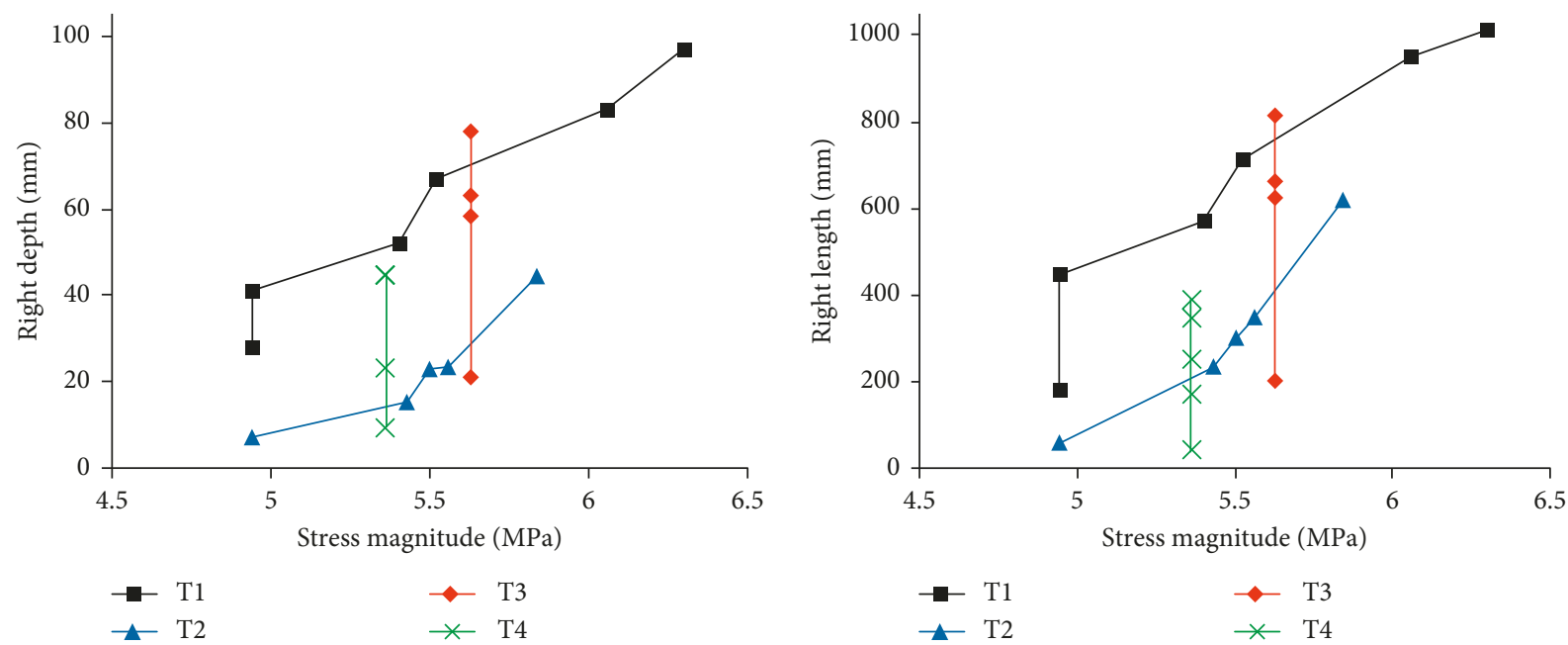

(c)

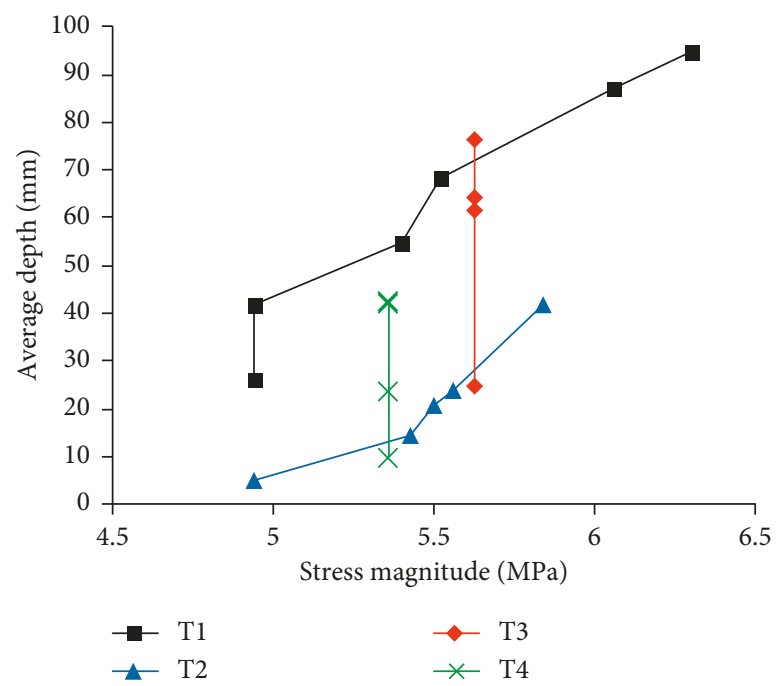

(e)

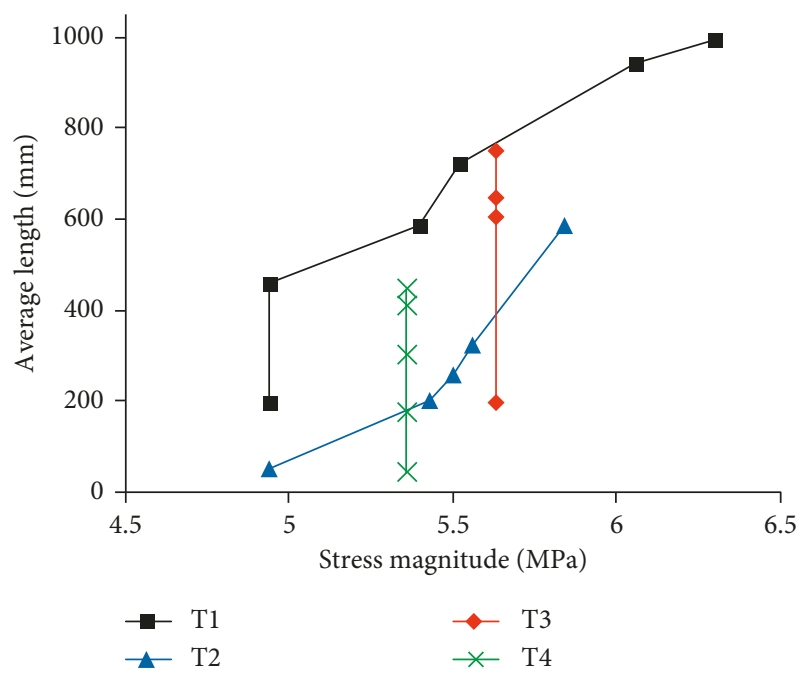

(f)

Figure 19: The length and depth of crack for three load paths. (a) Left depth. (b) Right depth. (c) Left length. (d) Right length. (e) Average depth. (f) Average length. 


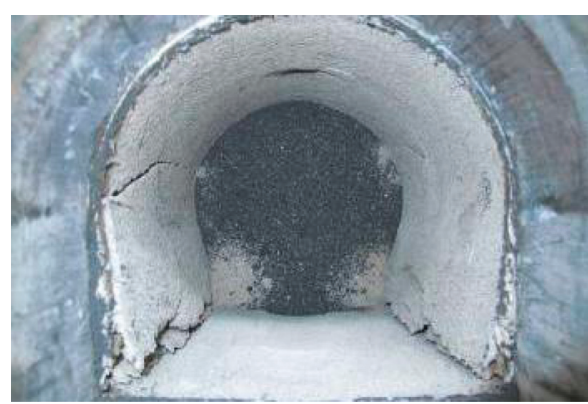

(a)

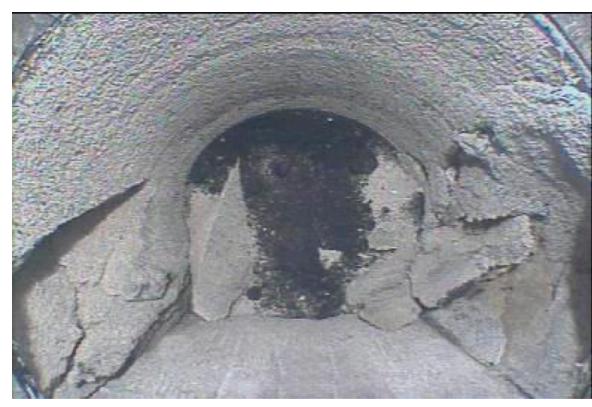

(c)

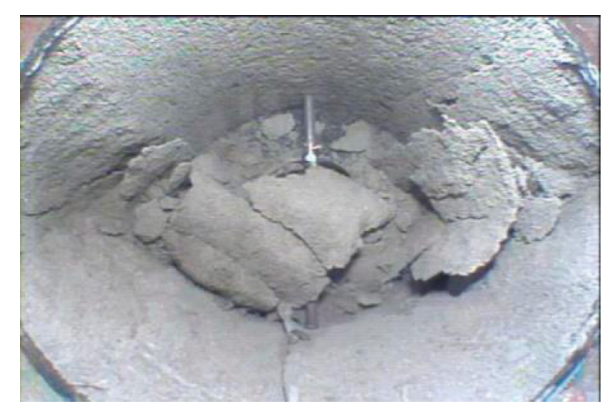

(b)

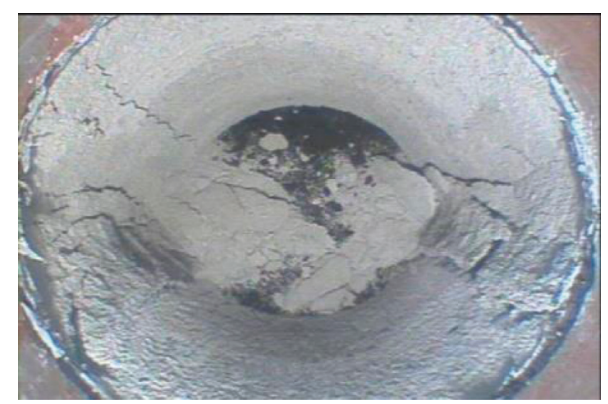

(d)

Figure 20: Model tunnels after load-testing. (a) Tunnel T1. (b) Tunnel T2. (c) Tunnel T3. (d) Tunnel T4.

The failure effect and bearing capacity of the tunnel are affected by the loading rate. The failure of the inner wall of the four tunnel models under the maximum load in physical model tests is shown in Figure 20. The damage process to deep tunnels at different loading rates can be found by comparing the mechanical responses of tunnel models with different loading schemes. When the loading rate is low, the stress applied to the physical model was mainly borne by the surrounding rock at greater deep and further from the tunnel. With the gradual increase in applied stress, the damage developed from the side wall to depth in the surrounding rock. When the loading rate was high, the failure of the model material mainly occurred in the surrounding rock adjacent to the side wall: the higher the loading rate, the more severe the damage to the surface of the inner wall of the tunnel. As can be seen from Figure 19, when the loading rate was low, the deformation of the surrounding rock of the tunnel was larger. For instance, the convergence between the left side wall and the right side wall of tunnel $\mathrm{T} 1$ was greater than that of tunnel T3 and the convergence between the roof and floor of tunnel $\mathrm{T} 2$ was greater than that of tunnel T4. In short, different damage effects will occur in tunnels under different loading rates. When the loading rate is low, small deformations occur in the tunnel, but the depth and degree of the damage are severe. When the loading rate is high, large deformations occur in the tunnel and severe damage occurs on the surface.

\section{Conclusions}

In this paper, the process of crack propagation and tunnel failure in a deep tunnel under high ground stress conditions, as affected by the cross-sectional shape of tunnel, was quantified by carrying out several large-scale physical model tests: four physical models with two section shapes and twelve stress levels were tested.

(1) The failure depth generated in the rock surrounding the horseshoe tunnel is about several times that of the circular tunnel under the same stress. Under compressive load, continuous spalling occurred at the foot of the horseshoe tunnel and discontinuous spalling occurred at the midheight of the side wall of the circular tunnel.

(2) Microcracks in the rock surrounding a horseshoe tunnel develops upwards in a conjugate sliding shape to the foot of the arch roof, finally the cracks coalesced. For the circular tunnel, microcracks in the surrounding rock extend concentrically to greater depth in the rock surrounding the tunnel.

(3) Under a vertical compressive load, tensile failure mainly occurs on the surface of the side wall and shear failure mainly occurs in the surrounding rock. The position of deepest damage of the horseshoe tunnel is at the $1 / 4$ height of the side wall and that is at the midheight of the side wall for circular tunnel.

(4) The effect of the cross-sectional shape on process of cracking propagation was decreased with increasing load. But even when the circular tunnel is loaded to the maximum applied stress, there are fewer cracks occurring in surrounding rock of circle tunnel than that of horseshoe tunnel.

It should be noted that we do not, in this work, consider the influence of heterogeneity. Some experimental tests will 
be carried out to study the influence of heterogeneity on the stability of the tunnel in future work.

\section{Abbreviations}

$H$ : Height

$R: \quad$ Radius or span

$R_{\mathrm{c}}$ : Compressive strength

$R_{\mathrm{t}}$ : Tensile strength

$C$ : Cohesion

$\Phi: \quad$ Internal friction angle

E: Modulus of elasticity

$\mu$ : Poisson's ratio

$\rho: \quad$ Density

$K_{i}$ : Similarity ratio of parameter $i$

$K_{H}$ : Similarity ratio of height

$K_{R}$ : Similarity ratio of span or radius

$K \rho$ : Similarity ratio of density

$K g$ : Similarity ratio of gravitational acceleration

$K_{R_{t}}$ : Similarity ratio of tensile strength

$K_{R_{c}}$ : Similarity ratio of compressive strength

$K_{C}:$ Similarity ratio of cohesion

$K_{\varphi}$ : Similarity ratio of internal friction angle

$K_{\mu}$ : Similarity ratio of Poisson's ratio

$K_{E}$ : Similarity ratio of elastic modulus

$i_{\mathrm{m}}$ : Parameter $i$ of tunnel model

$H_{\mathrm{m}}$ : Height of tunnel model

$R_{\mathrm{m}}$ : Radius or span of tunnel model

$R_{\mathrm{cm}}$ : Compressive strength of tunnel model

$R_{\mathrm{tm}}$ : Tensile strength of tunnel model

$C_{\mathrm{m}}$ : Cohesion of tunnel model

$\Phi_{\mathrm{m}}$ : Internal friction angle of tunnel model

$E_{\mathrm{m}}$ : Modulus of elasticity of tunnel model

$\mu_{\mathrm{m}}$ : Poisson's ratio of tunnel model

$\rho_{\mathrm{m}}$ : Density of tunnel model

$i_{\mathrm{p}}$ : Parameter $i$ of the tunnel prototype

$H_{\mathrm{p}}$ : Height of tunnel prototype

$R_{\mathrm{p}}$ : Radius of span of tunnel prototype

$R_{\mathrm{cp}}$ : Compressive strength of tunnel prototype

$R_{\mathrm{tp}}$ : Tensile strength of tunnel prototype

$C_{\mathrm{p}}$ : Cohesion of tunnel prototype

$\Phi_{\mathrm{p}}$ : Internal friction angle of tunnel prototype

$E_{\mathrm{p}}$ : Modulus of elasticity of tunnel prototype

$\mu_{\mathrm{p}}$ : Poisson's ratio of tunnel prototype

$\rho_{\mathrm{p}}$ : Density of tunnel prototype.

\section{Data Availability}

The data used to support the findings of this study are available from the corresponding author upon request.

\section{Conflicts of Interest}

The authors declare that there are no conflicts of interest regarding the publication of this paper.

\section{Acknowledgments}

This work was supported by the National Key R\&D Programme of China (2016YFC0801400 and 2016YFC0600700),
Open Fund of State Key Laboratory of Water Resource Protection and Utilization in Coal Mining (Grant no. SHJT17-42.10), National Natural Science Foundation of China (Grant no. 51804309) and State Key Laboratory of Coal Resources and Safe Mining (China University of Mining and Technology, under Grant nos. SKLCRSM16KFB07, SKLCRSM16DCB01 and SKLCRSM17DC11), Key Laboratory of Coal Mine Safety and High-Efficiency Mining as coestablished by the Province and the Ministry (JYBSYS2018201), Yue Qi Distinguished Scholar Project, China University of Mining and Technology, Beijing, and Young Elite Scientists Sponsorship Program by CAST (2017QNRC001). All of these supports are gratefully acknowledged.

\section{References}

[1] X. Zhang, Q. Gao, S. Cui, and C. Duan, "Research on failure mechanism and parameter sensitivity of zonal disintegration in deep tunnel," Advances in Civil Engineering, vol. 2019, Article ID 5678427, 10 pages, 2019.

[2] B. Mobaraki and M. Vaghefi, "Numerical study of the depth and cross-sectional shape of tunnel under surface explosion," Tunnelling and Underground Space Technology, vol. 47, pp. 114-122, 2015.

[3] A. Z. Lu, H. Y. Chen, Y. Qin, and N. Zhang, "Shape optimisation of the support section of a tunnel at great depths," Computers and Geotechnics, vol. 61, pp. 190-197, 2014.

[4] Q. B. Meng, L. J. Han, W. G. Qiao, D. G. Lin, and L. C. Wei, "Numerical simulation of cross-Section shape optimization design of deep soft rock roadway under high stress," Journal of Mining \& Safety Engineering, vol. 29, no. 5, pp. 650-656, 2012.

[5] G. C. Li, N. Zhang, C. Wang, N. C. Zhang, and B. Y. Li, "Optimizing the section shape of roadways in high stress ground by numerical simulation," Journal of China University of Mining \& Technology, vol. 39, no. 5, pp. 652-658, 2010.

[6] D. P. Ma, Y. J. Yang, J. S. Cao, and L. Y. Xing, "Optimization design of cross section shape of deep roadways based on characteristics of energy release," Journal of Central South University, vol. 46, no. 9, pp. 3354-3360, 2015.

[7] J. Xu, J. Jiang, N. Xu, Q. Liu, and Y. Gao, "A new energy index for evaluating the tendency of rockburst and its engineering application," Engineering Geology, vol. 230, pp. 46-54, 2017.

[8] Z. He and B. Wang, "Instability process model test for bedding rock slope with weak interlayer under different rainfall conditions," Advances in Civil Engineering, vol. 2018, Article ID 8201031, 8 pages, 2018.

[9] X. Liu, S. Yang, X. Ding, C. Zhang, X. Wang, and B. Zhou, "Physical simulation and monitoring the deformation and fracture of roadway in coal mining," Advances in Civil Engineering, vol. 2018, Article ID 2607957, 10 pages, 2018.

[10] S.-c. Li, C. Hu, L.-p. Li, S.-g. Song, Y. Zhou, and S.-s. Shi, "Bidirectional construction process mechanics for tunnels in dipping layered formation," Tunnelling and Underground Space Technology, vol. 36, pp. 57-65, 2013.

[11] M. Kiani, T. Akhlaghi, and A. Ghalandarzadeh, "Experimental modeling of segmental shallow tunnels in alluvial affected by normal faults," Tunnelling and Underground Space Technology, vol. 51, pp. 108-119, 2016.

[12] S. C. Li, Q. Wang, H. T. Wang et al., "Model test study on surrounding rock deformation and failure mechanisms of deep roadways with thick top coal," Tunnelling and Underground Space Technology, vol. 47, pp. 52-63, 2015. 
[13] M. Lei, L. Peng, and C. Shi, "Model test to investigate the failure mechanisms and lining stress characteristics of shallow buried tunnels under unsymmetrical loading," Tunnelling and Underground Space Technology, vol. 46, pp. 64-75, 2015.

[14] L. Jiang, P. Wang, P. Zheng, H. Luan, and C. Zhang, "Influence of different advancing directions on mining effect caused by a fault," Advances in Civil Engineering, vol. 2019, Article ID 7306850, 10 pages, 2019.

[15] X.-m. Sun, F. Chen, M.-c. He, W.-l. Gong, H.-c. Xu, and H. Lu, "Physical modeling of floor heave for the deep-buried roadway excavated in ten degree inclined strata using infrared thermal imaging technology," Tunnelling and Underground Space Technology, vol. 63, pp. 228-243, 2017.

[16] H.-M. Chen, H.-S. Yu, and M. J. Smith, "Physical model tests and numerical simulation for assessing the stability of bricklined tunnels," Tunnelling and Underground Space Technology, vol. 53, pp. 109-119, 2016.

[17] Y. Fang, C. Xu, G. Cui, and B. Kenneally, "Scale model test of highway tunnel construction underlying mined-out thin coal seam," Tunnelling and Underground Space Technology, vol. 56, pp. 105-116, 2016.

[18] W. Shen, W. Guo, H. Nan, C. Wang, Y. Tan, and F. Su, "Experiment on mine ground pressure of stiff coal-pillar hard roof," Advances in Civil Engineering, vol. 2018, Article ID 2629871, 11 pages, 2018.

[19] F. Huang, H. Zhu, Q. Xu, Y. Cai, and X. Zhuang, "The effect of weak interlayer on the failure pattern of rock mass around tunnel-scaled model tests and numerical analysis," Tunnelling and Underground Space Technology, vol. 35, pp. 207218, 2013.

[20] Y. Li, D. Zhang, Q. Fang, Q. Yu, and L. Xia, “A physical and numerical investigation of the failure mechanism of weak rocks surrounding tunnels," Computers and Geotechnics, vol. 61, pp. 292-307, 2014.

[21] H. Fu, J. Zhang, Z. Huang, Y. Shi, and W. Chen, "A statistical model for predicting the triaxial compressive strength of transversely isotropic rocks subjected to freeze-thaw cycling," Cold Regions Science and Technology, vol. 145, pp. 237-248, 2018.

[22] D. Guo, B. Zhou, K. Liu, R. Yang, and P. Yan, "Dynamic caustics test of blast load impact on neighboring different cross-section roadways," International Journal of Mining Science and Technology, vol. 26, no. 5, pp. 803-808, 2016.

[23] S. Ma, Y. Shao, Y. Liu, J. Jiang, and X. Fan, "Responses of pipeline to side-by-side twin tunnelling at different depths: 3D centrifuge tests and numerical modelling," Tunnelling and Underground Space Technology, vol. 66, no. 4, pp. 157-173, 2017.

[24] C. Q. Zhang, H. Zhou, and X. T. Feng, "An index for estimating the stability of brittle surrounding rock mass: FAI and its engineering application," Rock Mechanics and Rock Engineering, vol. 44, no. 4, pp. 401-414, 2011.

[25] X.-T. Feng, X.-J. Hao, Q. Jiang, S.-j. Li, and J. A. Hudson, "Rock cracking indices for improved tunnel support design: a case study for columnar jointed rock masses," Rock Mechanics and Rock Engineering, vol. 49, no. 6, pp. 2115-2130, 2016. 


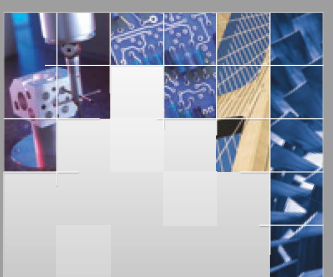

\section{Enfincering}
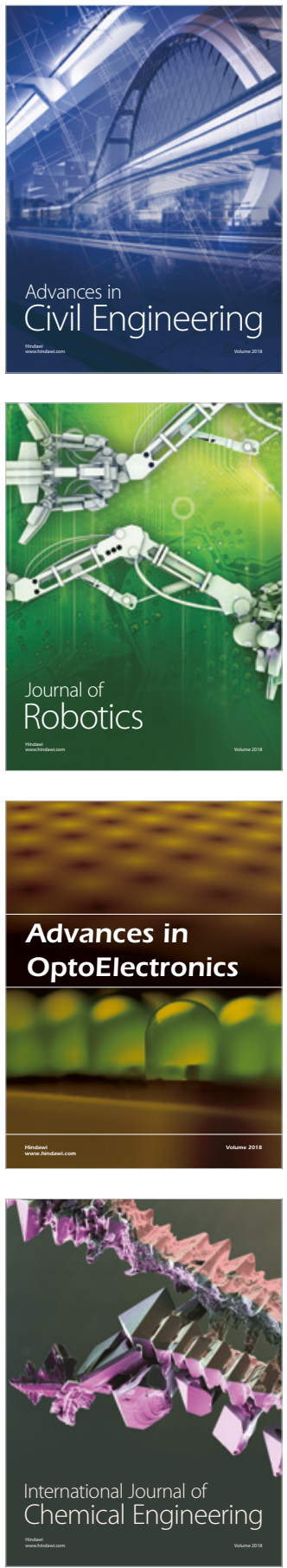

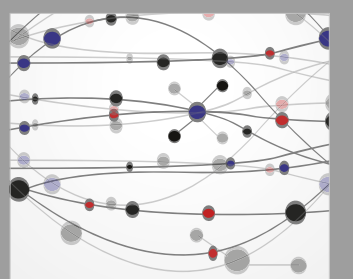

\section{Rotating \\ Machinery}

The Scientific World Journal

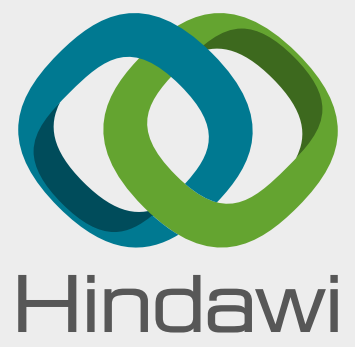

Submit your manuscripts at

www.hindawi.com
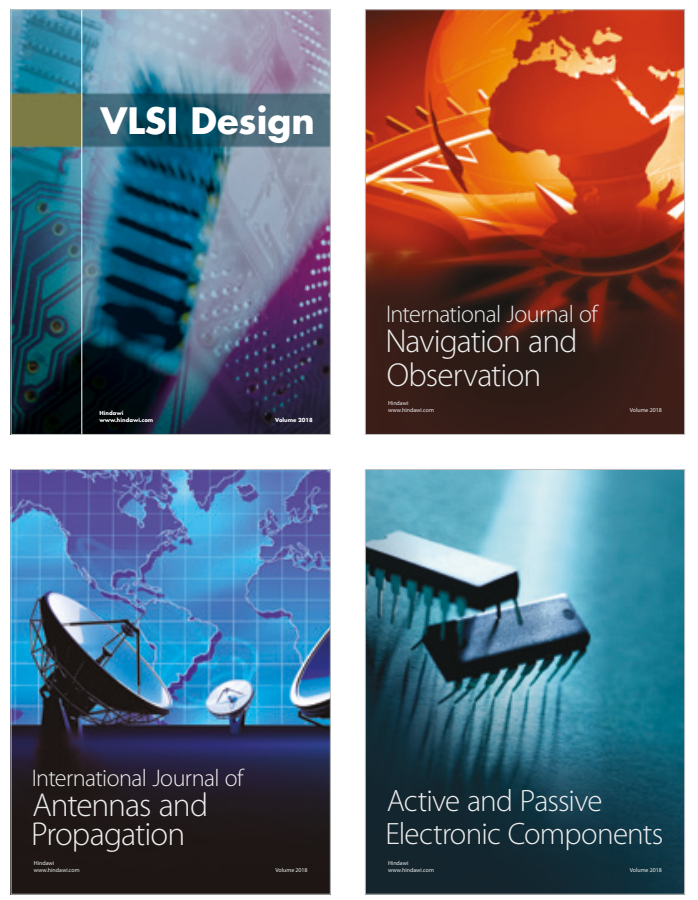
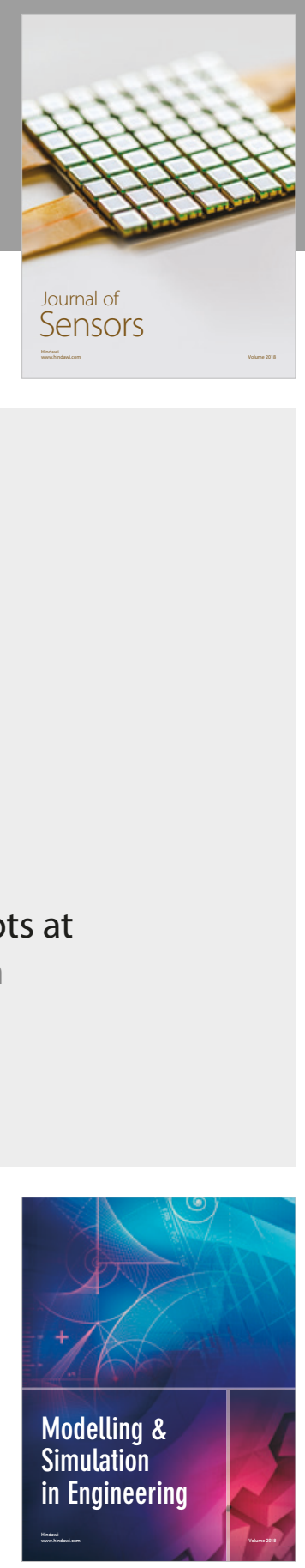

\section{Advances \\ Multimedia}
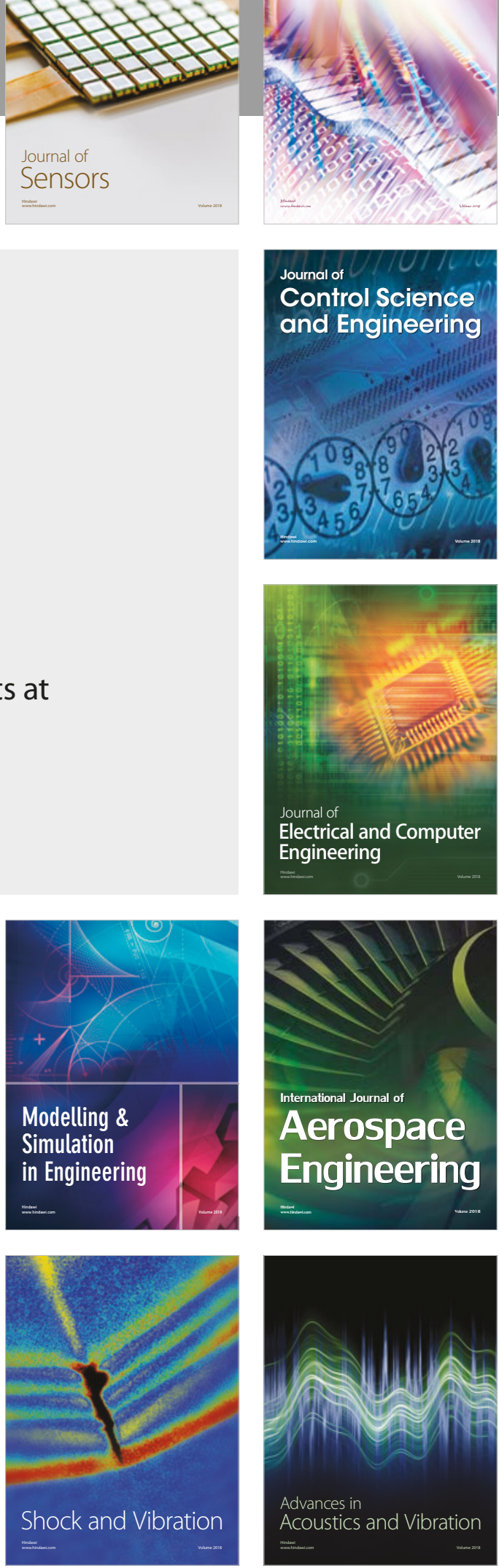